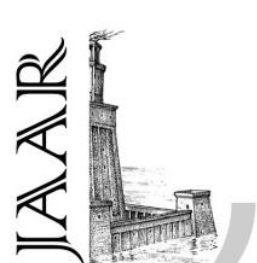

Since 1996

An Economic Study of The Most Important Problems and Obstacles Facing Bean Farmers in Agricultural Greenhouses in Dakahlia Governorate During The Emerging Corona Virus Pandemic

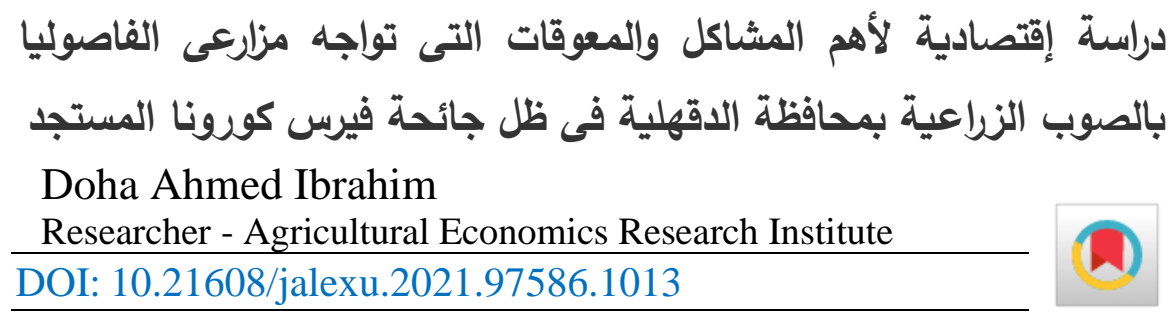

Article Information

Received:June $21^{\text {th }} 2021$

Revised: August $26^{\text {th }} 2021$

Accepted:September $27^{\text {th }}$ 2021

Published: October $12^{\text {th }}$ 2021
ABSTRACT: Greenhouse projects, especially those that grow vegetable crops, are considered among the most profitable projects, as these projects lead to bridging the gap between supply and demand of these crops, in addition to increasing farmers' income, which leads to raising the standard of living of farmers, and providing opportunities Work for young graduates, and those resulting crops can be exported to foreign markets, especially European markets, opening new markets for Egyptian agricultural exports, which leads to an increase in agricultural exports, reducing the deficit in the agricultural balance, and providing hard currency for the state.Despite the importance of greenhouse projects in increasing agricultural production, mitigating the seasonal phenomenon of agricultural production, reducing unemployment, and reducing the gap between supply and demand in agricultural crops resulting from greenhouses, whether in local markets or exporting them to foreign markets. Despite the high return results of growing vegetable crops in greenhouses, where the productivity of one acre of greenhouses increases six times what traditional agriculture produces of those crops, but these projects still suffer from some economic and productivity problems, which leads to poor spread.

The research relied on the descriptive statistical analysis method, the use of Cronbach's alpha coefficient to measure the validity and reliability of the research sample, and the chi-square test to analyze the problems of the research sample. The research was based on primary data, through questionnaires, which were collected from the farmers of the study crops in Dakahlia Governorate, during interviews with farmers. The research also relied on secondary data published on: The website of the Economic Affairs Sector, and some researches, theses, studies, and scientific books related to the topic of research were used. The research aims at an economic study of the most important problems and obstacles facing Green beans farmers in greenhouses in Dakahlia Governorate, in light of the Corona virus, through: (1) identifying the most important problems and obstacles facing Green beans farmers in greenhouses and study the proposing appropriate solutions to them. (2) Identifying the impact of the Corona virus on the greenhouse project for the Green beans crop by study sample. (3) Studying the most important factors affecting the Corona virus, on the greenhouse project for the Green beans crop by study sample.It was found that the most important factors affecting the Corona virus, to the project of planting Green beans crop in greenhouses in study sample, are the financing problems, marketing problems, as they represent important variables in influencing, the Corona virus on, the project of planting the Green beans crop in greenhouses, so The researcher recommends paying attention to solving the financing and marketing problems of their impact on the project of cultivating the Green beans crop in greenhouses, in the research sample in Dakahlia Governorate.

Keywords: greenhouses - Green beans crop - Covid 19

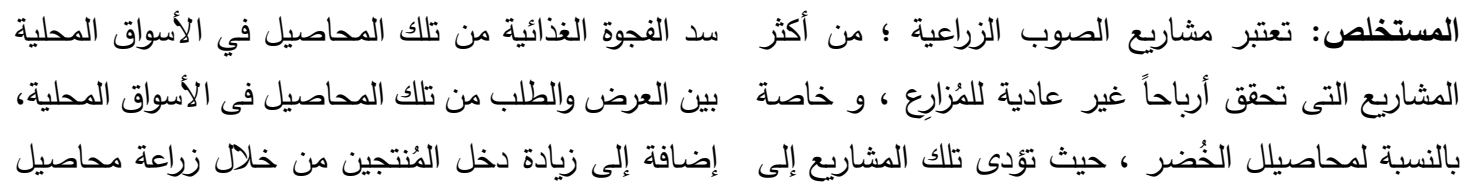
Journal Article (C) 2021 by (JAAR) is licensed under CC BY-NC 4.0 CC) 
الفاصوليا بعينة الدراسة في ظل جائحة فيروس كورونا

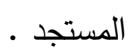

وتمثلت أهم العوامل المؤثرة على مشروع زراعة محصول

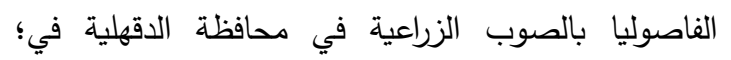

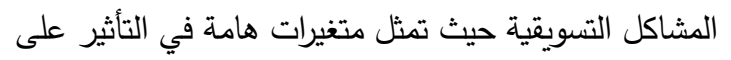

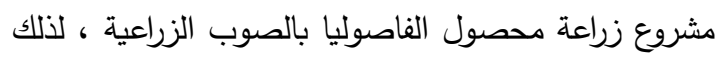

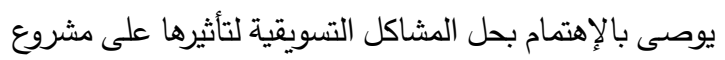
زراعة محصول الفاصوليا بالصوب الزراعية بالعينة البحثية

بمحافظة الدقهلية.

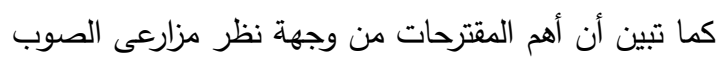

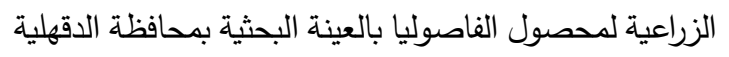

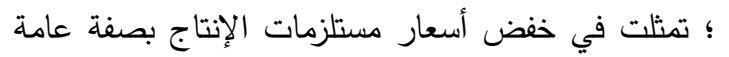

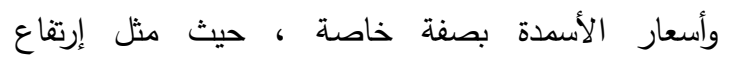
أسعارالأسمدة حوالى 50.8 \% بليها خفض أسعار التقاوى الأس

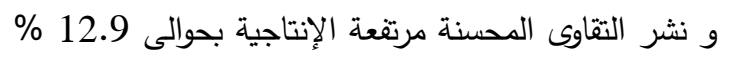

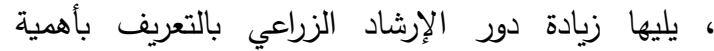

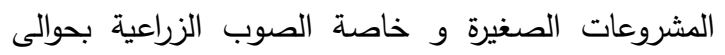

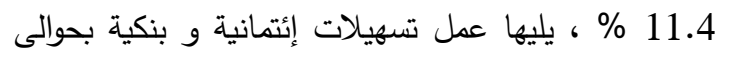
9.8 \% 9.8 ثم خفض أسعار مستلزمات إنثاء الصوب الزراعية

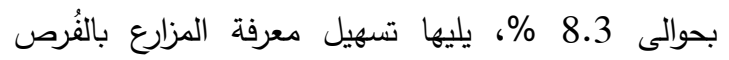

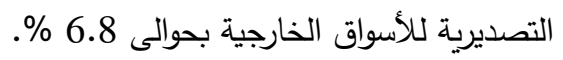
الكلمات الدلالية : الصوب الزراعية ـ محصول الفاصوليا .

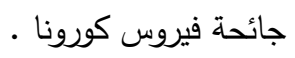

مقدمسة: تعتبر مشكلة نقص الغذاء و تحقيق الإكتفاء الذاتى للسلع

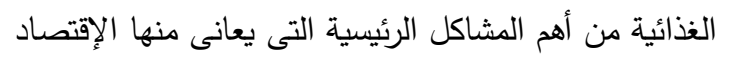

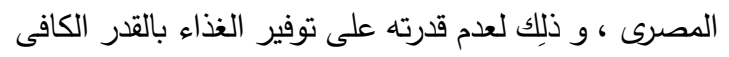

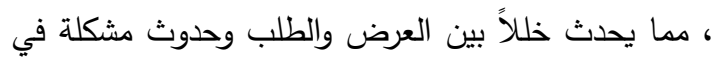
الأمن الغذائى المصري ، الأمر الذي يتطلب معه تضافر لئر

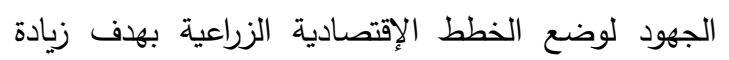

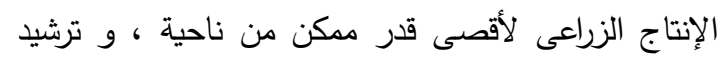

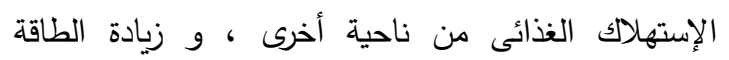

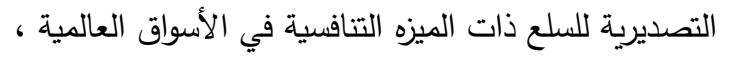

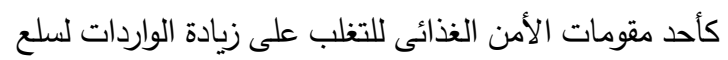

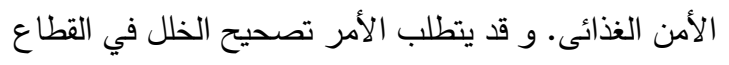

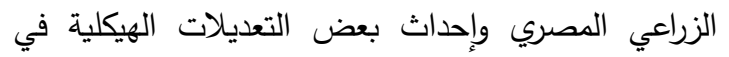
السياسات الزراعية بأقسامها المُختلفة ، بالإضافة إلى إجراء

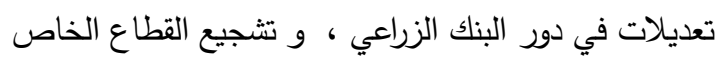

عالية القيمة تحقق دخول مرتفعة، مما يؤدى لرفع مستوى

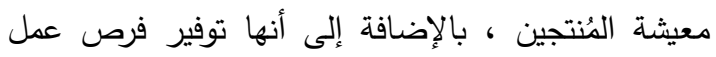
لثباب الخريجين ، كما يمكن تصدير الفائض من المحاصيل

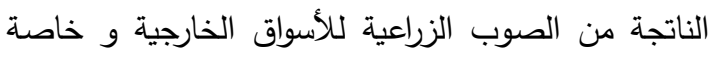

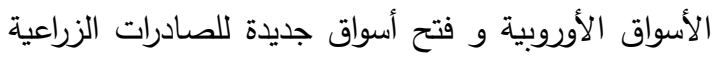

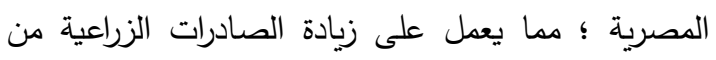
محاصيل الخُضر و خفض العجز فى الميزان التجاري الزراعى المصري ، والذي يعاني عجزاً مستمراً مُنُْ سبعينات من القرن الماضي و توفير عملة صعبة للدولة.

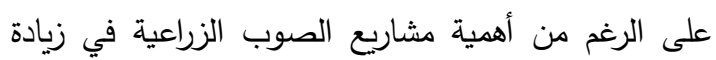

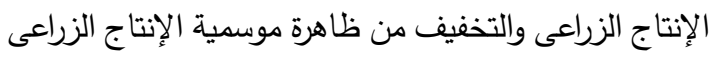

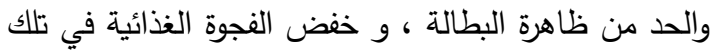

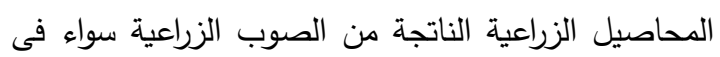

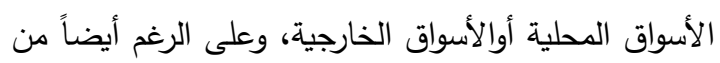

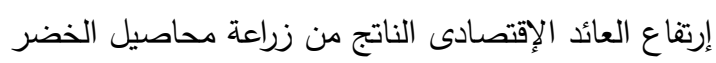

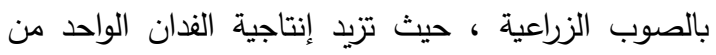

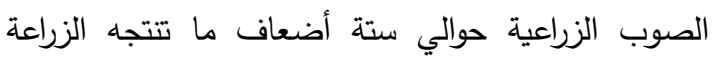
المكثوفة من تلك المحاصيل؛ الإ أن تلك المشاريع لا تزال

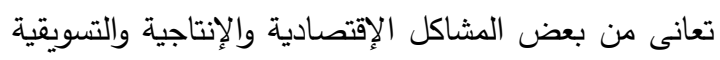
بها ، مما يؤدى إلى ضعف إنتشار مثل هذه المشاريع بين المزارعين ، و قد يرجع ذلك بسبب إرتفاع تكلفة إنشائها.

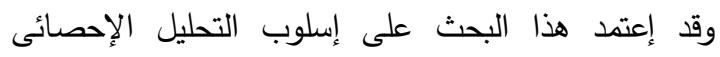

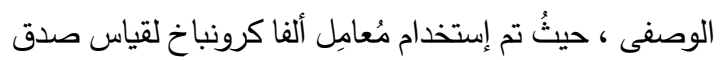

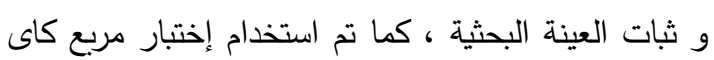

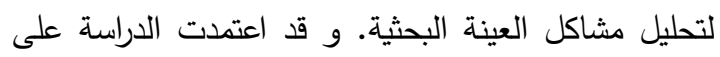
البيانات الأولية من خلال إستمارات إستبيان تم تجميعها من إندات

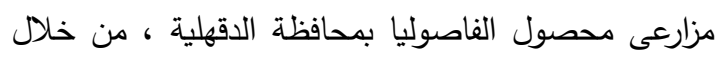

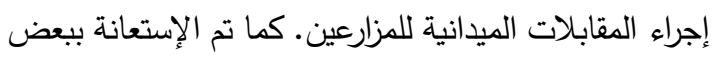
الأبحاث والرسائل والدراسات والكتب العلمية التي لها صلة التهاتل بموضوع البحث. و يستهاف البحث دراسة إقتصادية لأهم

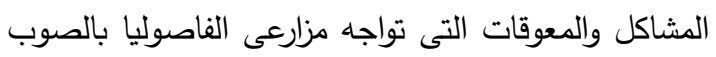
الزراعية بححافظة الدقهلية فى ظل جائحة فيروس كورونا المستجد من خلال : (1) التعرف على أهم المشاكل والمعوقات التى تواجه مزارعى الفاصوليا بالصوب الزئل الزراعية

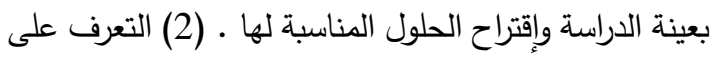
أثز جائحة فيروس كورونا المستجد على مشروعات إنتاج الفاصوليا بالصوب الزراعية بعينة الدراسة.(3) دراسة أهم

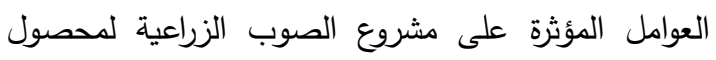




\section{الأهداف البحثية:}

يستهدف البحث دراسة أهم المشاكل والمعوقات التى تواجه

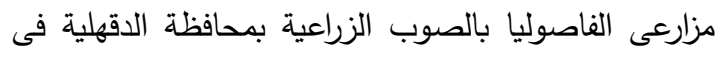

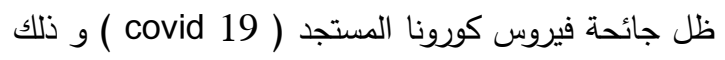

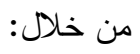
1. التعرف على أثر فيرس كورونا المستجد على مشروعات إنتاج الفاصوليا بالصوب الزراعية بعينة الدراسة.

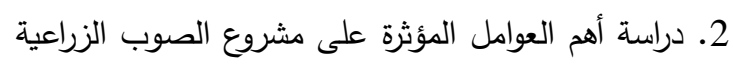

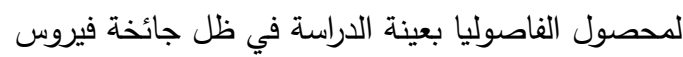

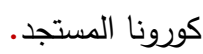
3. التعرف على أهم المشاكل والمعوقات التى تواجه مزارعى التى

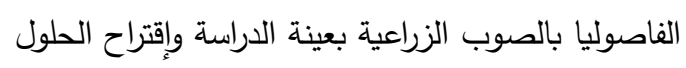
المناسبة لها. الإسلوب البحثي ومصادر البيانات:

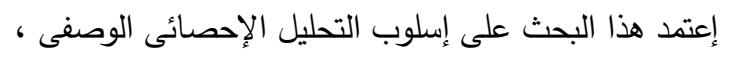

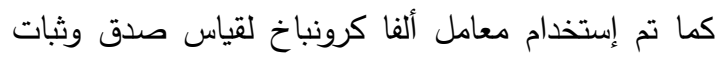
العينة البحثية وإختبار مربع كاى لتحليل مشاكل العينة

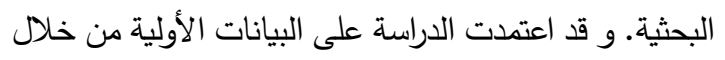

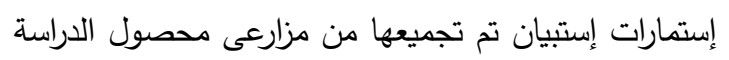

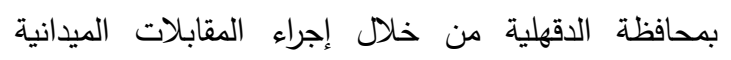

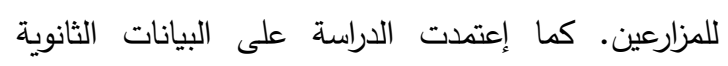

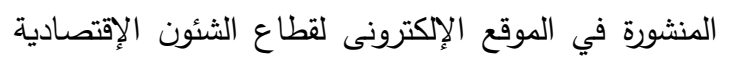

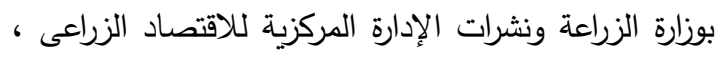

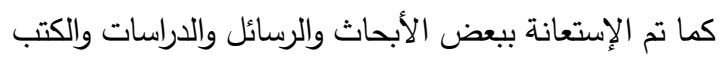

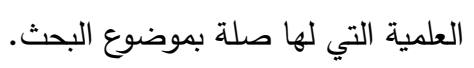
النتائج البحثية والمناقثة

تم إجراء استبيان لعدد 30 استمارة إستبيان لمزارعى محصول الفاصوليا بالصوب الزراعية بمحافظة الدقهلية عن أثر جائحة

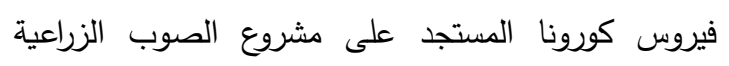
لمحصول الفاصوليا ، و قد أوضحت نتائج العينة البحثية الآتي : المعال:

أولاً: الخصائص الايموجرافية لمزارعى الصوب الزراعية بمحصول الفاصوليا بعينة الدراسة :

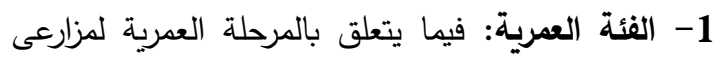

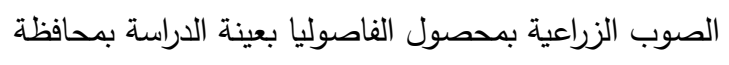
الدقهلية فقد أوضحت نتائج الدراسة أن الفئة العمرية الثالثة والتي تتراوح من 40 سنة لأقل من 50 عاماً كانت هي الفئة الغالبة لمزارعى الصوب الزراعية لمحصول الفاصوليا بعينة
و شباب الخريجين علي استزراع الأراضي الجديدة والإتجاه

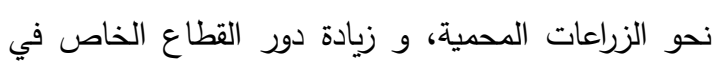

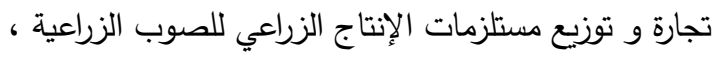
وإتخاذ بعض التسهيلات فى الإجراءات البنكية ، وإزالة

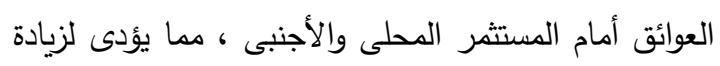

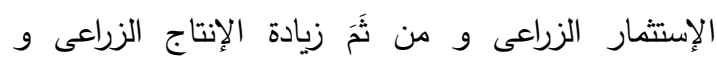

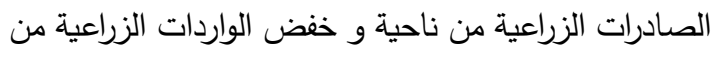

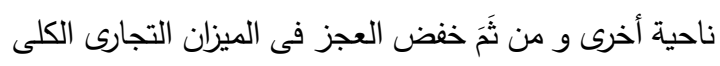

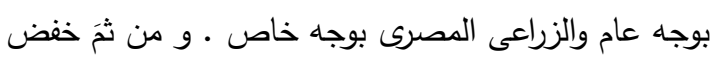
العجز في الميزانية العامة للدولة . المشكلة البحثية: تعتبر مشاريع الصوب الزراعية ؛ من أكثر المشاريع التى

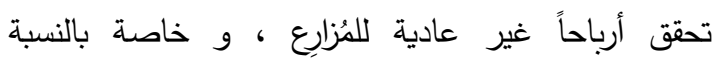
لمحاصيلل الخُضر ، حيث تئدى تلك المشاريع إلى سد الفجوة

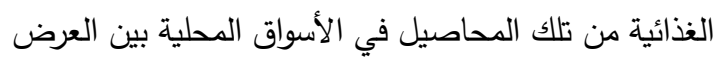
والطلب من تلك المحاصيل فى الأسواق المحلية، إضافة إلى لى زيادة دخل الكُنتجين من خلال زراعة محاصيل عالية القيمة تحقق دخول مرتفعة، مما يؤدى لرفع مستوى معيشة المُنتجين

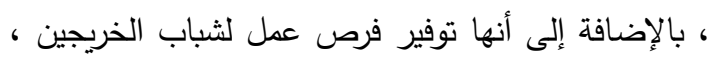

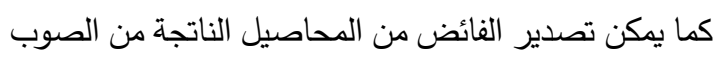
الزراعية للأسواق الخارجية و خاصة الأسواق الأوروبية و

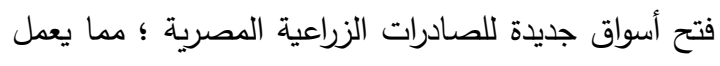

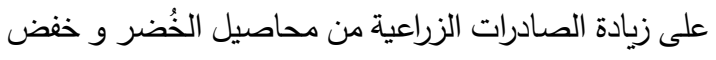

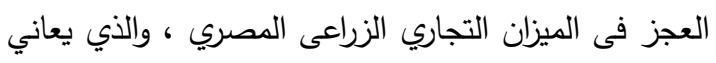

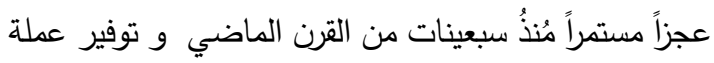

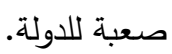

على الرغم من أهمية مشاريع الصوب الزراعية في زيادة

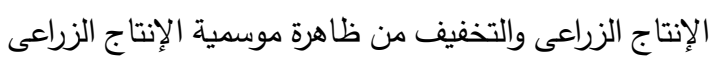

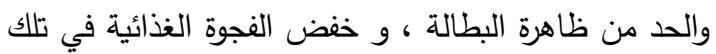
المحاصيل الزراعية الناتجة من الصوب الزراعية سواء فى النى

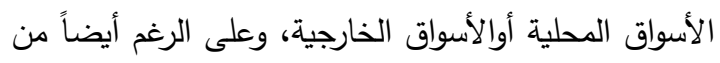

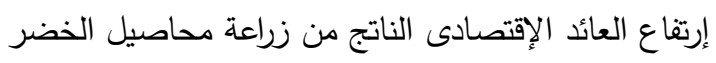

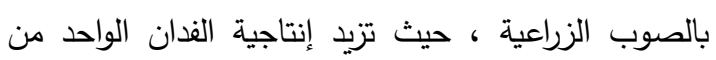

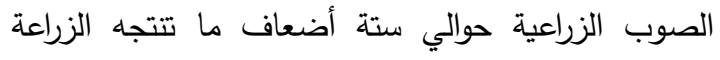
المكثوفة من تلك المحاصيل؛ الإ أن تلك المشاريع لا تزال

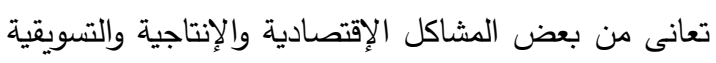

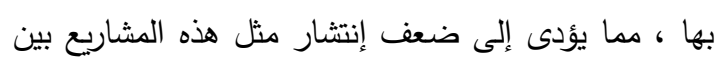
المزارعين ، و قد يرجع ذلك بسبب إرتفاع تكلفة إنشائها. 
نسبته حوالي 30\% ، ثم المستوى التعليمى الجامعى حيث

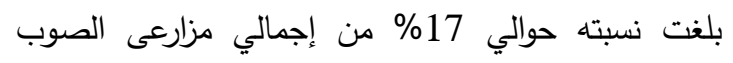
الزراعية بحصول الفاصوليا بعينة الدراسة بمحافظة الدقهلية-

\section{جدول (1).}

ولعل الإثارة إلى قيم الوسط الحسابي المرجح للفئة العمرية

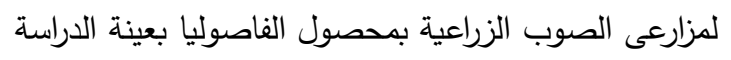

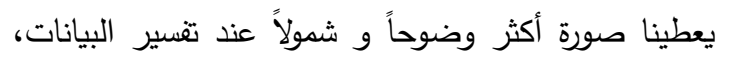
حيث بلغ الوسط الحسابي المرجح حوالي 3 بوزن نسبى مرجح بلغ حوالي 0.78 ، أي أنها تقع في الفئة الثالثة والتي تتراوح

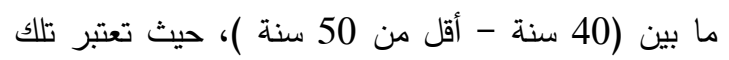

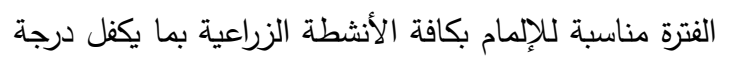

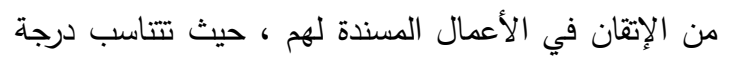

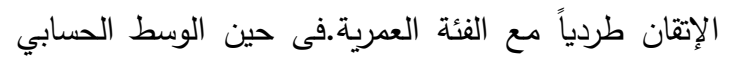

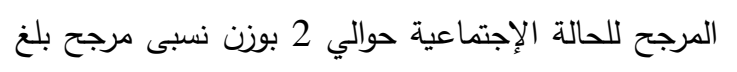

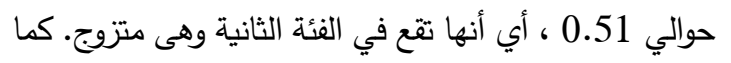

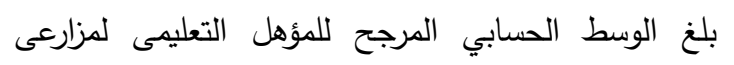

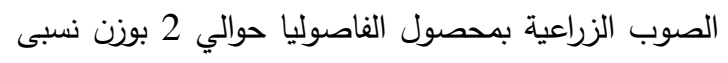

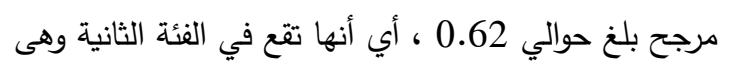

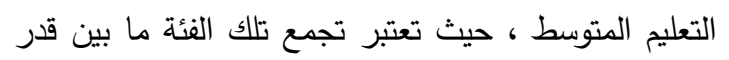

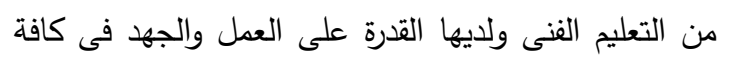

الأنشطة العملية.
الدراسة حيث بلغت نسبتها حوالي 43\% ، يليها الفئة العمرية

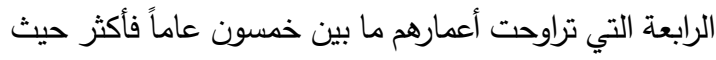
بلغت نسبتهم حوالي 37\% من إجمالي مزارعى الصوب

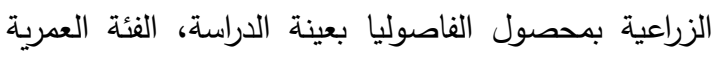

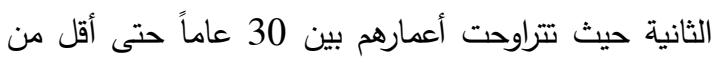

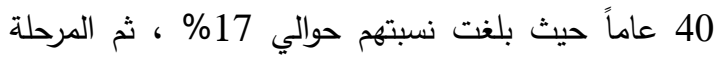

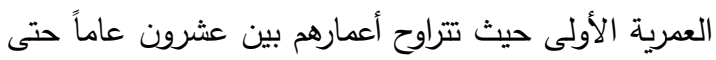

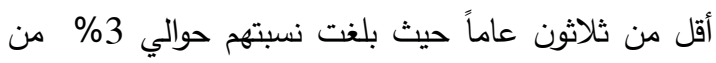
إجمالي مزارعى الصوب الزراعية بمحصول الفاصوليا بعينة الدراسة بدحافظة الدقهلية- جدول (1). 2- الحالة الإجتماعية: أوضحت بيانات الدراسة أن الحالة

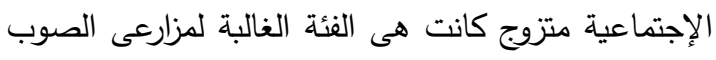

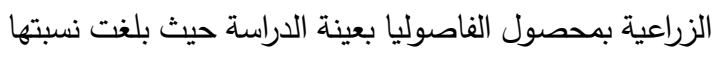

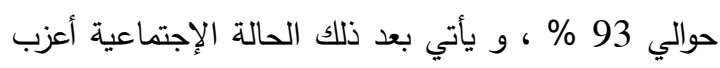
حيث بلغت نسبتها حوالي 4 \% ، ثم و الحالة الإجتماعية أرمل

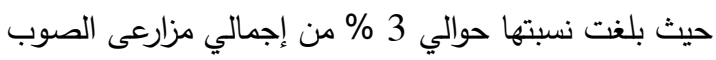
الزراعية بمحصول الفاصوليا بعينة الدراسة - جدول (1).

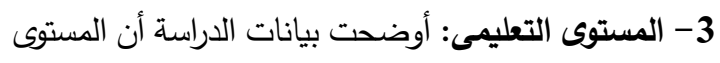

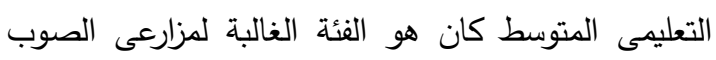

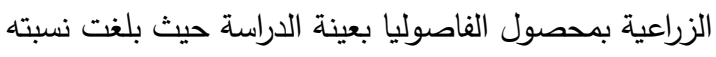

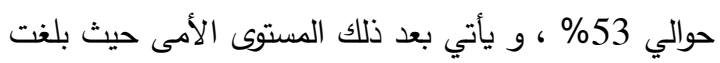

جدول رقم (1) : النتائج المرتبطة بخصائص مزارعى الصوب الزراعية بمحصول الفاصوليا بعينة الدراسة

\begin{tabular}{|c|c|c|c|c|c|}
\hline الترتيب & النسبة & عدد المفردات & المتغيرات & الرمز & الخصائص \\
\hline 4 & $\% 3$ & 1 & $30-20$ & أ- أ- & \multirow{4}{*}{ الفئة العمرية } \\
\hline 3 & $\% 17$ & 5 & $40-30$ & 1 & \\
\hline 1 & $\% 43$ & 13 & $50-40$ & ج- & \\
\hline 2 & $\% 37$ & 11 & 50- فأكثر & د- & \\
\hline- & 100 & 30 & \multicolumn{2}{|c|}{ المجمــوع } & \\
\hline 2 & $\% 4$ & 1 & أعزب & أ- أ- & \multirow{4}{*}{ الحالة الإجتماعية } \\
\hline 1 & $\% 93$ & 28 & متزوج & ب & \\
\hline- & $\% 0$ & 0 & مطلق & ج- & \\
\hline 3 & $\% 3$ & 1 & أرمل & د- & \\
\hline- & 100 & 30 & \multicolumn{2}{|c|}{ المجمــوع } & \\
\hline 2 & $\% 30$ & 9 & أمى & أ- أ - أ & \multirow{3}{*}{ المستوى التعليمى } \\
\hline 1 & $\% 53$ & 16 & تعليم متوسط & ب & \\
\hline 3 & $\% 17$ & 5 & مؤهل عالى & ج- & \\
\hline- & 100 & 30 & \multicolumn{2}{|c|}{ المجموع } & \\
\hline
\end{tabular}



كاي قد بلغت حوالي (23.59) بدرجات حرية 6، كما تبين

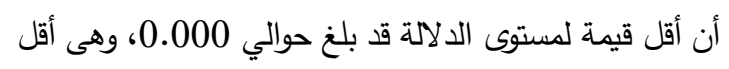

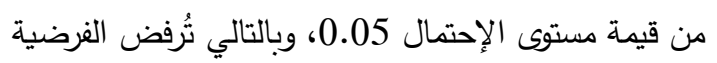

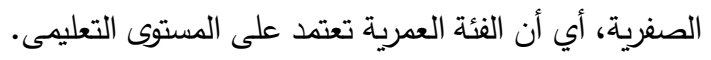

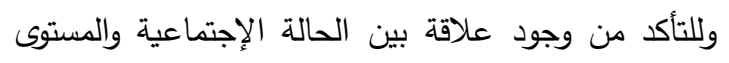
التعليمى فقد تم إجراء اختبار مربع كاي على بيانات العينة ، البحثية حيث تبين من نتائج جدول (2) أن قيمة مربع كاي التئي

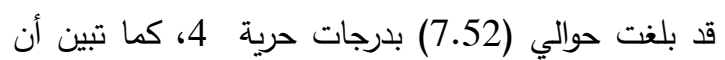
أقل قيمة لمستوى الدلالة قد بلغ حوالي 0.11 ، وهنى أكبر

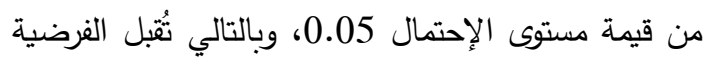

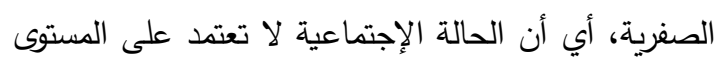

$$
\text { التعليمى. }
$$

العينة البحثية حيث تبين من نتائج جدول (2) أن قيمة مربع

4 - اختبار وجود علاقة بين متغيرات الدراسة الوصفية بمشروع الصوب الزراعية لمحصول الفاصوليا بعينة

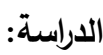
للتأكد من وجود علاقة بين الفئة العمرية والحالة الإجتماعية

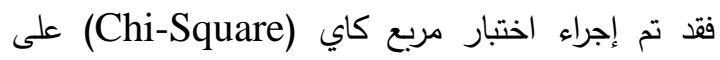
بيانات العينة البحثية حيث تبين من نتائج جدول (2) أن

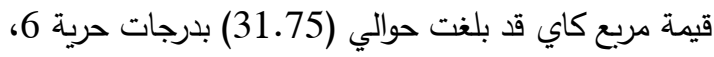

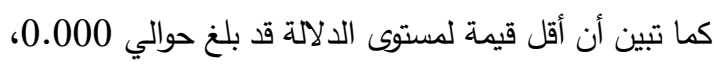

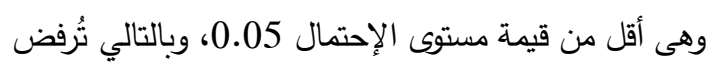
الفرضية الصفرية، أي أن الفئة العمرية تعتمد على الحالة العالة

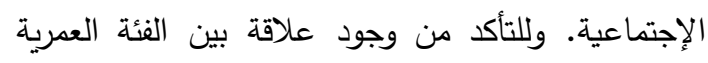
والمستوى التعليمى فقد تم إجراء اختبار مربع كاي على بيانات

جدول رقم (2) : نتائج اختبار مربع كاي للتأكد من وجود علاقة بين متغيرات الداسة الوصفية

\begin{tabular}{|c|c|c|}
\hline مستوى الدلالة & قيمة مربع كاي & المتغيرات \\
\hline 0.000 & 31.75 & الفئة العمرية X الحالة الإجتماعية \\
\hline 0.000 & 23.59 & الفئة العمرية X المستوى التعليمى \\
\hline 0.110 & 7.52 & الحالة الإجتماعية X المستوى التعليمى \\
\hline
\end{tabular}

المصدر : جمعت وحسبت من بيانات إستمارات الإستبيان بعينة الدراسة.

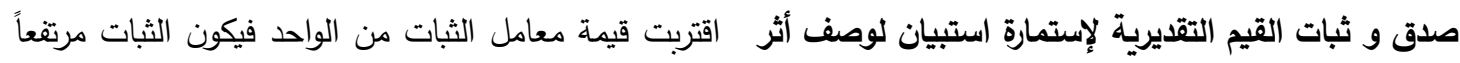

جائحة فيرس كورونا المستجد على مشروع الصوب وكلما اقتربت قيمته من الصفر فيكون الثبات منخفضاً.

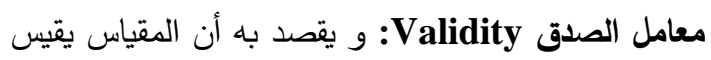
ما وضع لقياسه، حيث يعكس معامل الصدق الجذر التربيعي

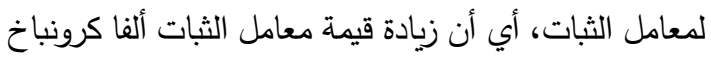

تعني زيادة مصداقية بيانات العينة. وقد تبين من نتائج جدول (3) أن معامل الثبات الداخلي (ألفا كرونباخ) قد بلغ حوالي 0.801 وهو مرتفع وموجب الإشارة

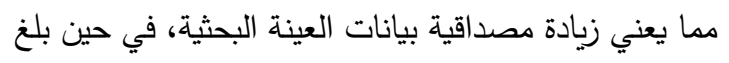

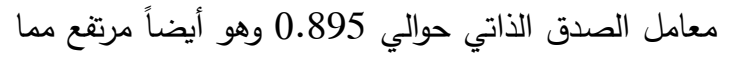
يثير إلى صدق بيانات العينة البحثية وبذلك يمكن الإعتماد الزراعية لمحصول الفاصوليا معامل الثبات Reliability Coefficient: يعني استقرار الدقياس وعدم تناقضه مع نفسه، أي أنه يعطي نفس النتائج إذا أعيد تطبيقه على نفس العينة، ولإجراء إختبار الثبات

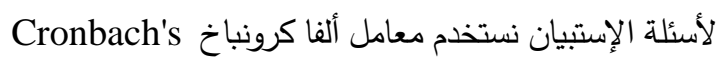
Alpha

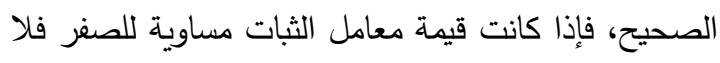

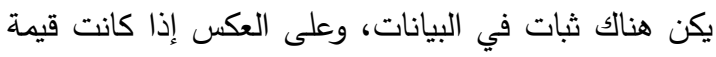
المعامل تساوي الواحد الصحيح فيكون هناك ثبات تام، وكلما على نتائجها فى الدراسة البحثي 
جدول رقم (3) : النتائج المرتبطة بمعامل الصدق والثبات لمحاور قياس أثر جائحة فيرس كورونا المستجد على مشروع الصوب الزراعية لمحصول الفاصوليا بالعينة البحثية

\begin{tabular}{|c|c|c|}
\hline 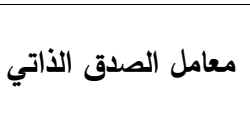 & $\begin{array}{c}\text { معامل الثبات الداخلي (ألفا- } \\
\text { كرونباخ) }\end{array}$ & المحاور \\
\hline 0.934 & 0.873 & أثر المشاكل التمويلية على مشروع الصوب الزراعية لمحصول الفاصوليا \\
\hline 0.863 & 0.745 & أثر المشاكل الإنتاجية على مشروع الصوب الزراعية لـحصول الفاصوليا \\
\hline 0.912 & 0.832 & أثر المشاكل التسويقية على مشروع الصوب الزراعية لدحصول الفاصوليا \\
\hline 0.924 & 0.854 & أثر فيرس كورونا المستجد على مشروع الصوب الزراعية لمحصول الفاصوليا \\
\hline 0.895 & 0.801 & 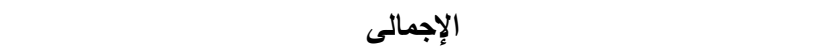 \\
\hline
\end{tabular}

المصدر : جمعت وحسبت من بيانات استمارة الإستبيان بعينة الدراسة .

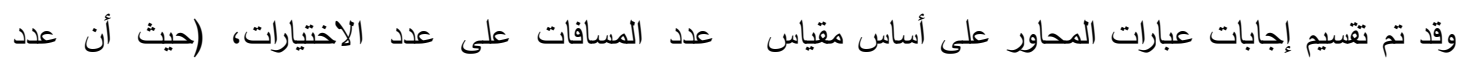

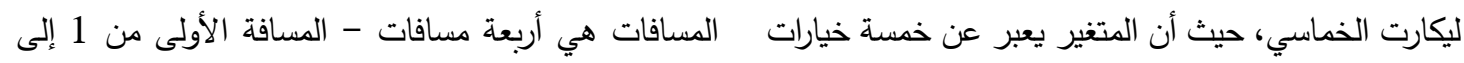

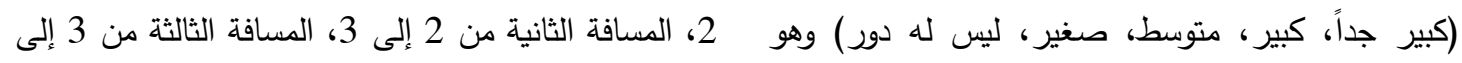

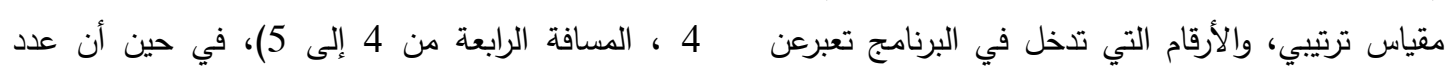

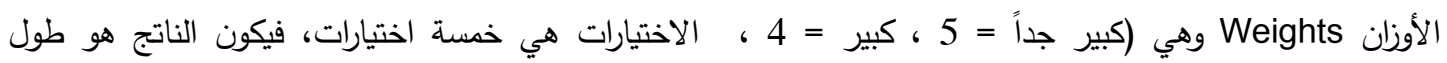

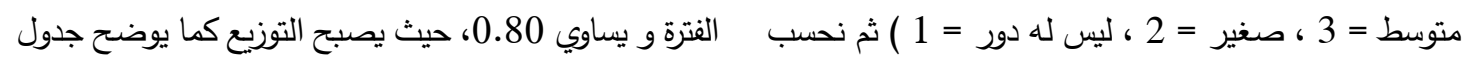

بعد ذلك المتوسط الحسابي (المتوسط المرجح). حيث يتم ل

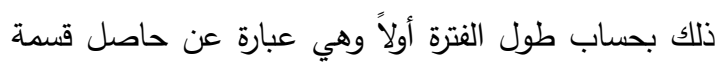
جدول رقم (4) : توزيع طول الفترة على حسب مقياس ليكارت الخماسي

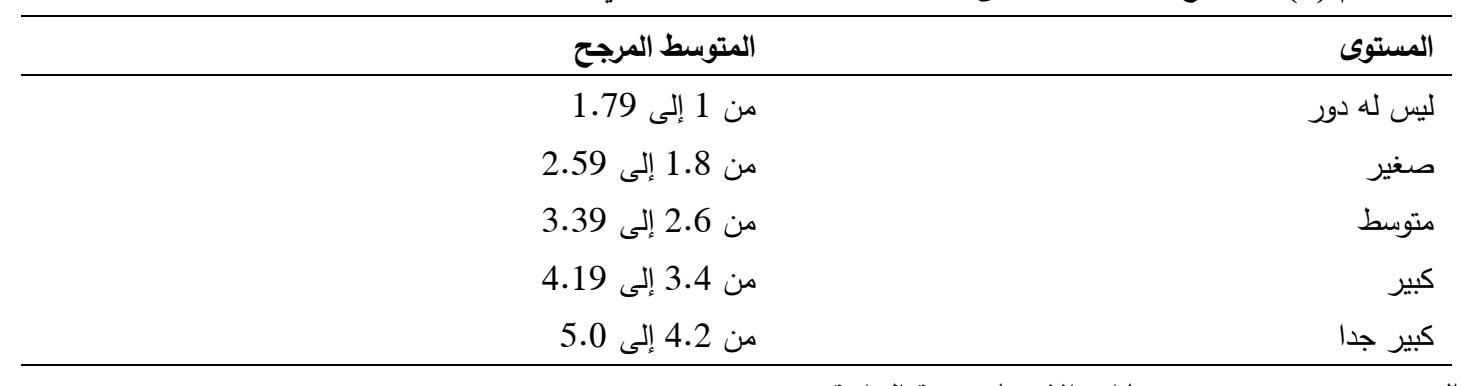

المصدر : حسبت من توزيع عبارات الإنتبيان بعينة الدراسة.

ثانياً : تحليل وتفسير نتائج الدراسة الميدانية المرتبطة بأثر المحور الرابع: بأثر فيرس كورونا المستجد على مشروع جائحة فيرس كورونا المستجد على مشروع الصوب الصوب الزبل الزراعية لمحصول الفاصوليا بعينة الدراسة.

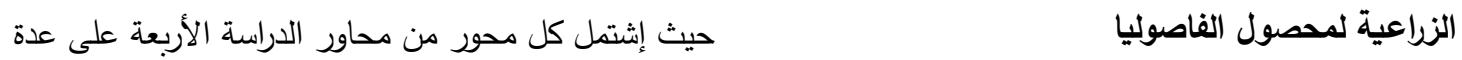
لدراسة أثر فيرس كورونا المستجد على مشروع الصوب عبارات فرعية.

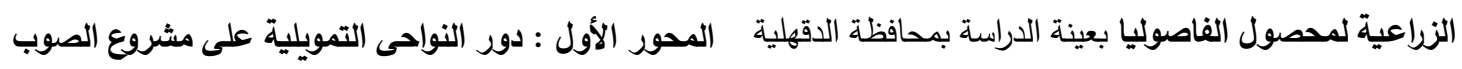

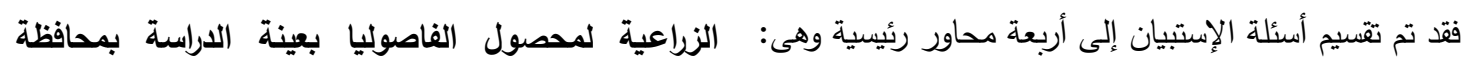

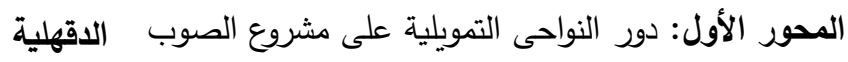
يضم المحور الأول دورالنواحى التمويلية في مشروع الصوب الزبه الزراعية لمحصول الفاصوليا بعينة الدراسة بمحافظة الدقهلية حيث إشتمل على ثلاث نقاط فرعية هى : الزراعية لمحصول الفاصوليا بعينة.

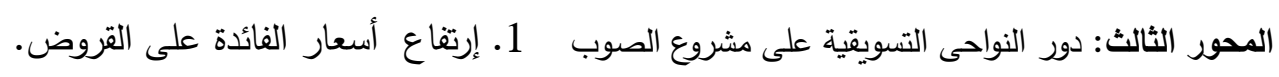
الزراعية لمحصول الفاصوليا بعينة الدراسة. 
أحد إلى وجود أهمية صغيرة ، بينما أشار حوالي 8.9\% إلى إلى

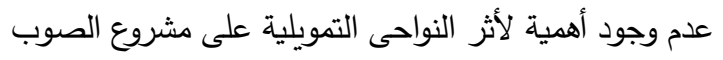
الزراعية لمحصول الفاصوليا. وفى ضوء نتائج الجدول السابق وبترتيب عبارات

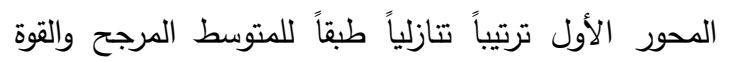

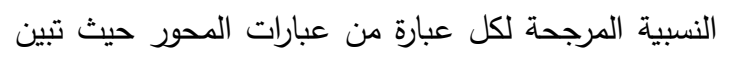
وفقاً للترتيب أن: الترتيب الأول: جاءت عبارة إرتفاع أسعار الفائدة على

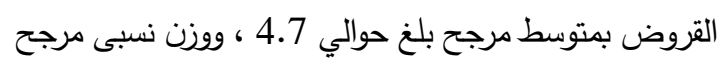

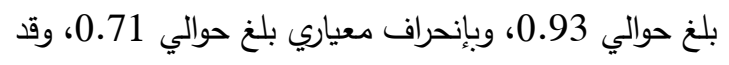

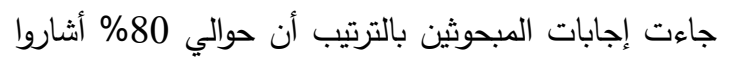

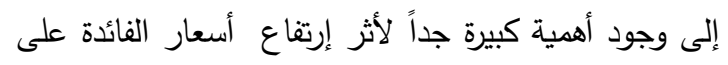

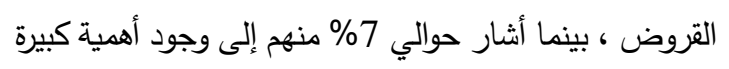

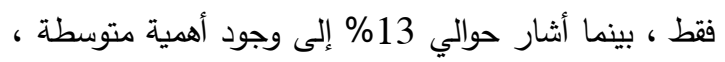

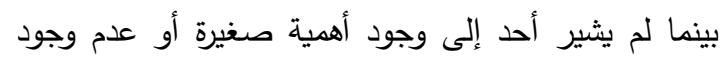

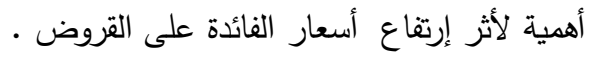

2. عدم وجود تسهيلات إئتمانية بنكية للحصول على القروض. - أن 3. ضعف قيمة القروض التمويلية. وفيما يلى تفصيل لعبارات ذلك المحور : تبين من خلال نتائج جدول (5) والذى يتعلق بأثر النواحى لئى التمويلية على مشروع الصوب الزراعية لمحصول الفاصوليا

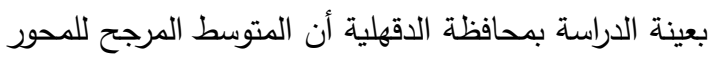
الأول قد بلغ حوالي 4.2 بإنحراف معياري بلغ حوالي 1.32

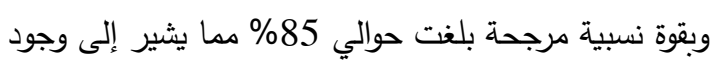
دلالة نسبية (كبيرة جداً) لأثر النواحى التمويلية على مشروع

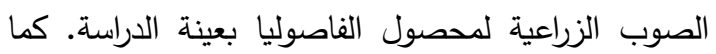
تثير النتائج إلى أن هناك حوالي 73.3 المصول من عينة الدراسة يؤكدون على وجود أهمية كبيرة جداً لأثر النواحى التمويلية

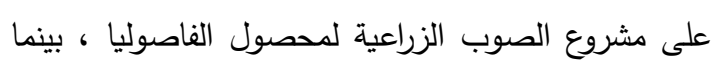

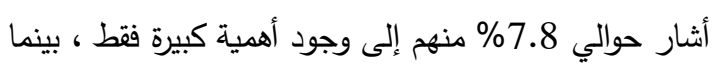
أشار حوالي 10\% إلى وجود أهمية متوسطة ، بينما لم يشير أهنير

جدول رقم (5) : دور النواحى التمويلية على مشروع الصوب الزراعية لمحصول الفاصوليا بعينة الاراسة بمحافظة الاقطلية

\begin{tabular}{|c|c|c|c|c|c|c|c|c|c|c|c|}
\hline الترتيب & النتيجة & المرجحة & الانحراف المعياري & المتوسط & ليس له & صغير & متوسط & 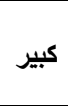 & كبير & & 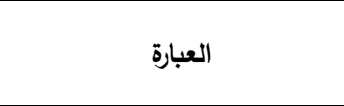 \\
\hline \multirow{2}{*}{1} & \multirow{2}{*}{ كبير جداً } & \multirow{2}{*}{0.93} & \multirow{2}{*}{0.71} & \multirow{2}{*}{4.7} & 0 & 0 & 4 & 2 & 24 & 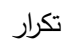 & 1-إرتفاع أسعار الفائدة على \\
\hline & & & & & 0 & 0 & 13 & 7 & 80 & $\%$ & القروض \\
\hline \multirow{2}{*}{2} & \multirow{2}{*}{ كبير جداً } & \multirow{2}{*}{0.85} & \multirow{2}{*}{1.41} & \multirow{2}{*}{4.3} & 4 & 0 & 2 & 2 & 22 & ت ت تكرار & 2-عدم وجود تسهيلات إئتمانية \\
\hline & & & & & 13 & 0 & 7 & 7 & 73 & $\%$ & بنكية للحصول على القروض \\
\hline \multirow{4}{*}{3} & \multirow{2}{*}{ كبير جداً } & \multirow{2}{*}{0.83} & \multirow{2}{*}{1.42} & \multirow{2}{*}{4.2} & 4 & 0 & 3 & 3 & 20 & 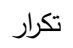 & \multirow{2}{*}{ 3-ضعف قيمة القروض التمويلية } \\
\hline & & & & & 13 & 0 & 10 & 10 & 67 & $\%$ & \\
\hline & \multirow[t]{2}{*}{ كبير جداً } & 0.85 & 1.32 & 4.2 & 8 & 0 & 9 & 7 & 66 & 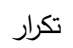 & المجموع \\
\hline & & & & & 8.9 & 0.0 & 10.0 & 7.8 & 73.3 & $\%$ & النسبة المئوبـة \\
\hline
\end{tabular}

المصدر : جمعت وحسبت من استمارات الاستبيان بعينة الدراسة.

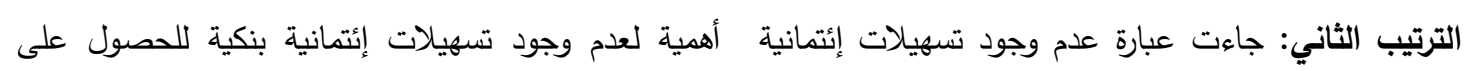

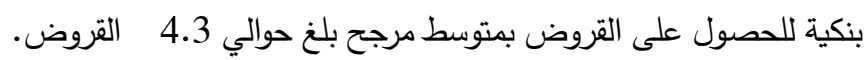

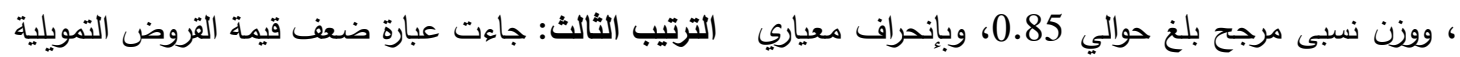

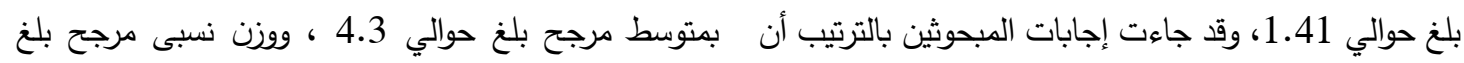

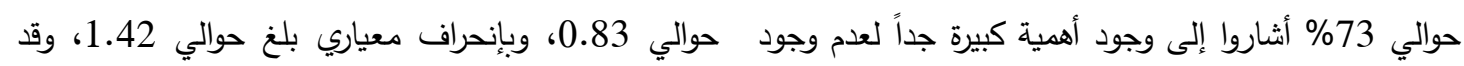

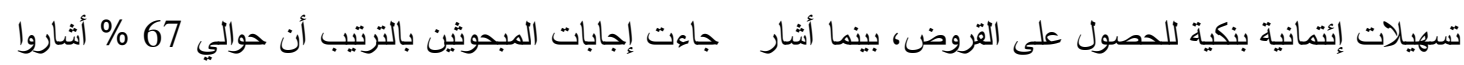

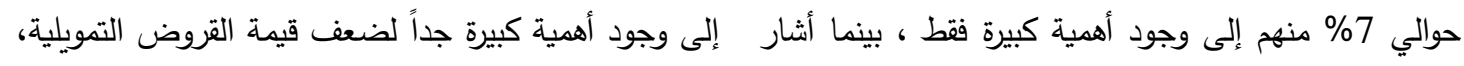

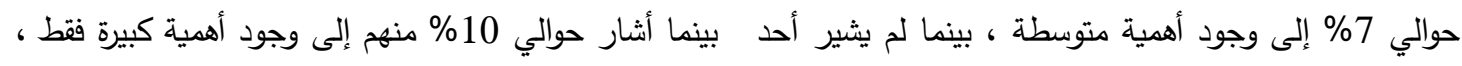

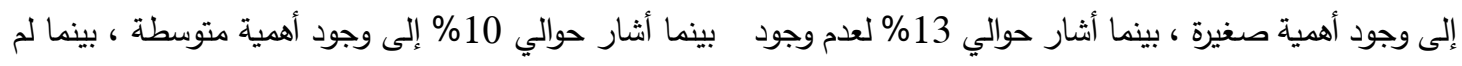


حوالي 0.97، وبإنحراف معياري بلغ حوالي 0.35، وقد

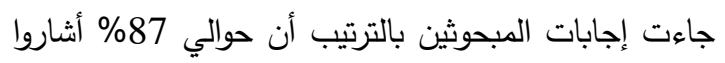

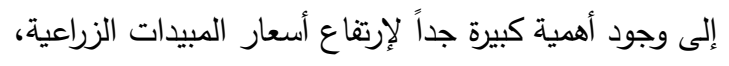

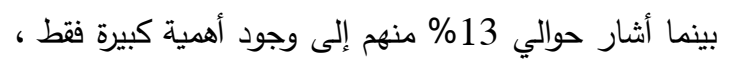

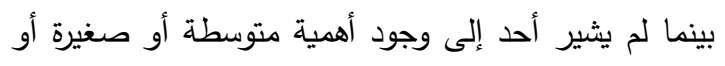
عدم وجود أهمية لإرتقاع أسعار المبيدات الزراعية.

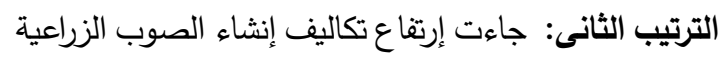

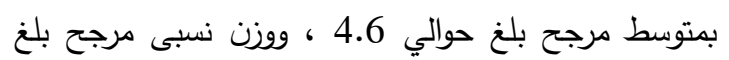

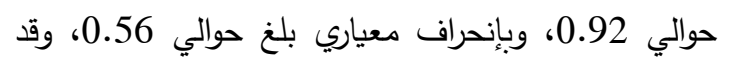

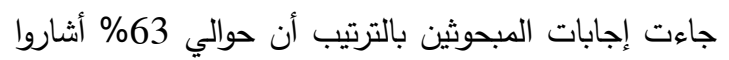

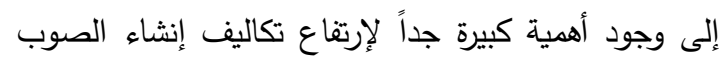

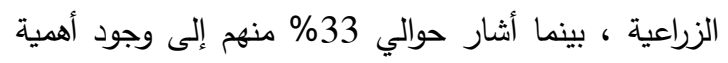

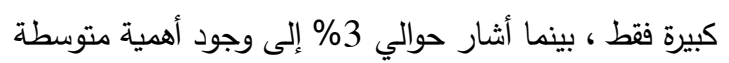

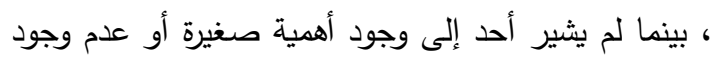
أهمية لإرتفاع تكاليف إنثاء الصوب الزبئ الزراعية.

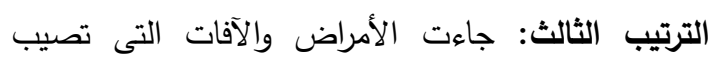
محاصيل الصوب الزراعية بمتوسط مرجح بلغ حوالي 4.5

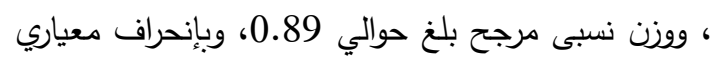

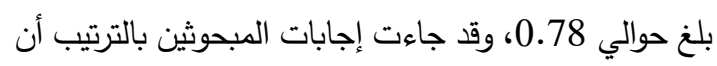
حوالي 63\% أشاروا إلى وجود أهمية كبيرة جداً لوجود

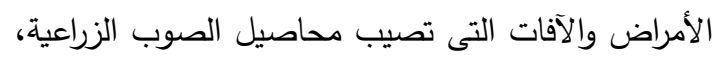

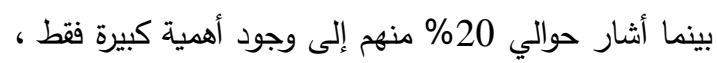

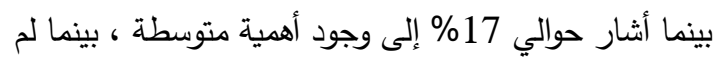

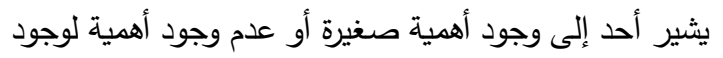
الأمراض والآفات التى تصيب محاصيل الصوب الزئلة الزراعية.

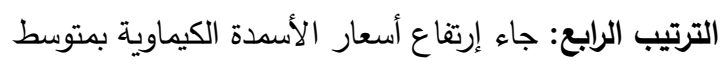

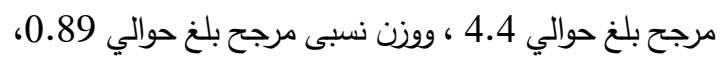

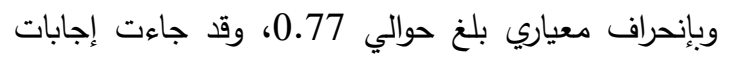

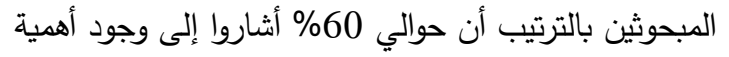

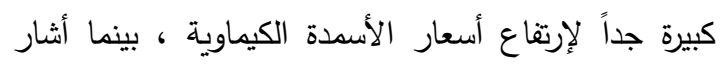

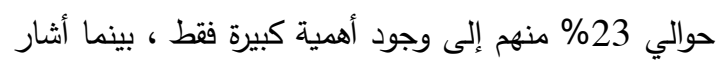

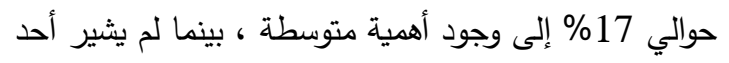

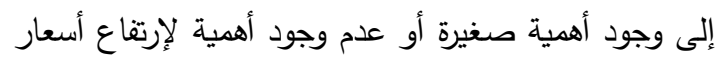
الأسمدة الكيماوية.

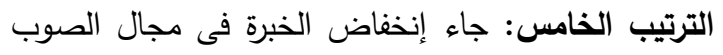
الزراعية بمتوسط مرجح بلغ حوالي 4.1 ، ووزن نسبى مرجح

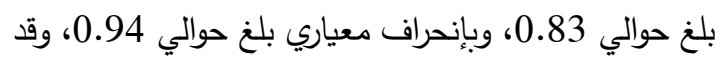

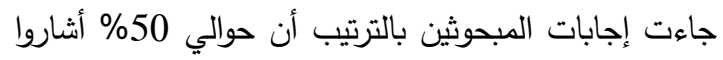

يشير أحد إلى وجود أهمية صغيرة ، بينما أشار حوالي 13\% إلى عدم وجود أهية لضعف قيمة القروض التمويلية. المحور الثانى : دور النواحى الإنتاجية في مشروع الصوب الزراعية لمحصول الفاصوليا بعينة الاراسة بمحافظة الدقهلية

يضم المحور الثانى دور النواحى الإتتاجية على مشروع الصوب الزراعية لمحصول الفاصوليا بعينة الدراسة بمحافظة الإنية الاقهلية حيث إثتمل على ستة نقاط فرعية هى : 1. إرتفاع أسعار الأسمدة الكيماوية. 2. إرتفاع أسعار المبيدات الزراعية. 3. إرتفاع تكاليف إنشاء الصوب الزراعية. 4. إنخفاض الخبرة فى مجال الصوب الزراعية

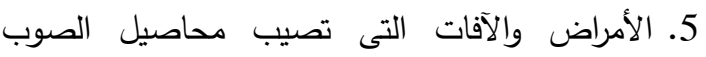
الزراعية 6. إرتفاع أجور الأيدى العاملة وفيما يلى تفصيل لعبارات ذلك المحور : تبين من خلال نتائج جدول (6) والذى يتعلق بأثر النواحى الإنتاجية على مشروع الصوب الزراعية لدحصول الفاصوليا بعينة الدراسة بمحافظة الدقهلية أن المتوسط المرجح للدحور الدئل الثانى قد بلغ حوالي 4.2 بإنحراف معياري بلغ حوالي 0.54 وبقوة نسبية مرجحة بلغت حوالي 85\% مما يشير إلى وجود دلالة نسبية (كبيرة جداً) لأثر النواحى الإنتاجية على مشروع

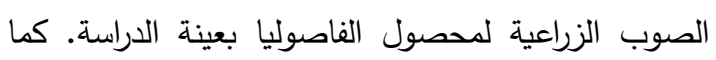
تثير النتائج إلى أن هناك حوالي 58.9 يؤكدون على وجود أهمية كبيرة جداً لأثر النواحى الإنتاجية على مشروع الصوب الزراعية لدحصول الفاصوليا ، بينما أشار حوالي 21.7\% منهم إلى وجود أهمية كبيرة فقط ، بينما أشار حوالي 18.9\% إلى وجود أهمية متوسطة ، بينما أثنار

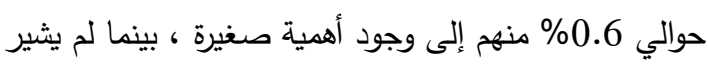
أحد إلى عدم وجود أهمية لأثر النواحى الإنتاجية على مشروع الهية الصوب الزراعية لمحصول الفاصوليا.

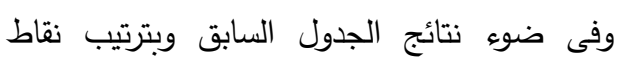

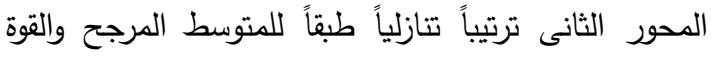
النسبية المرجحة لكل عبارة من عبارات المحور حيث تبين وفقاً للترتيب أن الترتيب الأول: جاءت إرتغاع أسعار المبيدات الزراعية

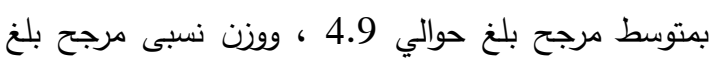


إلى وجود أهمية كبيرة جداً إنخفاض الخبرة فى مجال الصوب وبإنحراف معياري بلغ حوالي 0.91، وقد جاءت إجابات

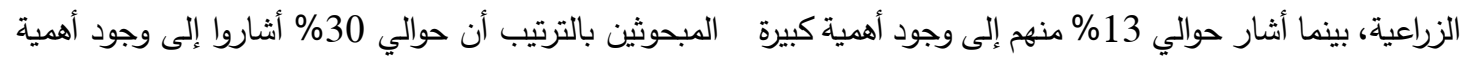

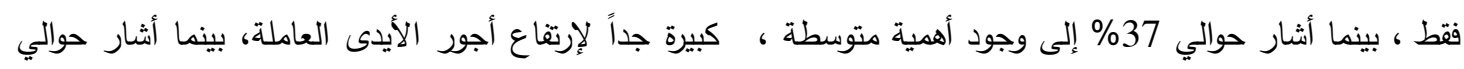

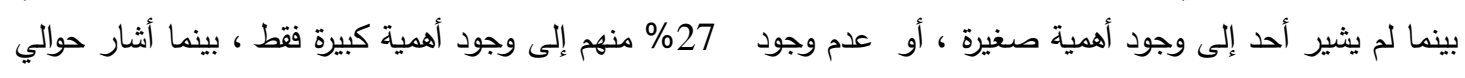

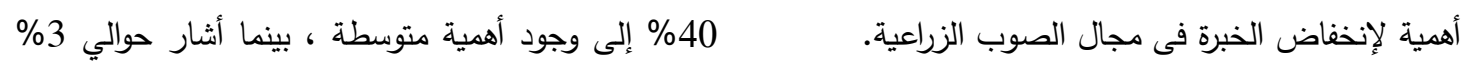

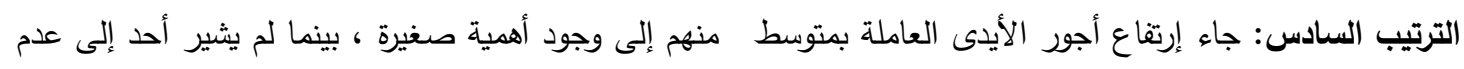
مرجح بلغ حوالي 3.8 ، ووزن نسبى مرجح بلغ حوالي 0.77، وجود أهمية لإرتفاع أجور الأيدى العاملة.

جدول رقم (6) : دور النواحى الإتتاجية على مشروع الصوب الزراعية لمحصول الفاصوليا بعينة الدراسة بمحافظة الدقهلية

\begin{tabular}{|c|c|c|c|c|c|c|c|c|c|c|c|}
\hline الترتيب & النتيجة & المرجحة & المعياري & المتوسط & ليس له & 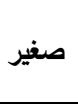 & متوسط & 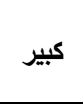 & كبير & & 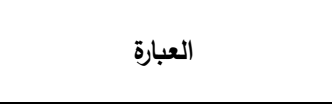 \\
\hline \multirow{2}{*}{4} & \multirow{2}{*}{ 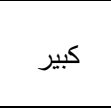 } & \multirow{2}{*}{0.89} & \multirow{2}{*}{0.77} & \multirow{2}{*}{4.4} & 0 & 0 & 5 & 7 & 18 & تكرار & 1-إرتفاع أسعار الأسمدة \\
\hline & & & & & 0 & 0 & 17 & 23 & 60 & $\%$ & الكيماوية \\
\hline \multirow{2}{*}{1} & \multirow{2}{*}{ كبير جداً } & \multirow{2}{*}{0.97} & \multirow{2}{*}{0.35} & \multirow{2}{*}{4.9} & 0 & 0 & 0 & 4 & 26 & 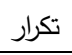 & 2-إرتفاع أسعار المبيدات \\
\hline & & & & & 0 & 0 & 0 & 13 & 87 & $\%$ & الزراعية \\
\hline \multirow{2}{*}{2} & \multirow{2}{*}{ كبير جداً } & \multirow{2}{*}{0.92} & \multirow{2}{*}{0.56} & \multirow{2}{*}{4.6} & 0 & 0 & 1 & 10 & 19 & تكرار & 3- إرتفاع تكاليف إنثاء \\
\hline & & & & & 0 & 0 & 3 & 33 & 63 & $\%$ & الصوب الزراعية \\
\hline \multirow{2}{*}{5} & \multirow{2}{*}{ 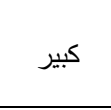 } & \multirow{2}{*}{0.83} & \multirow{2}{*}{0.94} & \multirow{2}{*}{4.1} & 0 & 0 & 11 & 4 & 15 & تكرار & 4-إنخفاض الخبرة فى مجال \\
\hline & & & & & 0 & 0 & 37 & 13 & 50 & $\%$ & الصوب الزراعية \\
\hline \multirow{2}{*}{3} & \multirow{2}{*}{ 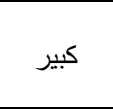 } & \multirow{2}{*}{0.89} & \multirow{2}{*}{0.78} & \multirow{2}{*}{4.5} & 0 & 0 & 5 & 6 & 19 & 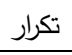 & 5-الأمراض والآفات التى تصيب \\
\hline & & & & & 0 & 0 & 17 & 20 & 63 & $\%$ & محاصيل الصوب الزراعية \\
\hline \multirow{4}{*}{6} & \multirow{2}{*}{ 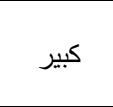 } & \multirow{2}{*}{0.77} & \multirow{2}{*}{0.91} & \multirow{2}{*}{3.8} & 0 & 1 & 12 & 8 & 9 & تكرار & \multirow{2}{*}{ 6-إرتفاع أجور الأيدى العاملة } \\
\hline & & & & & 0 & 3 & 40 & 27 & 30 & $\%$ & \\
\hline & \multirow[t]{2}{*}{ كبير جداً } & 0.85 & 0.54 & 4.2 & $\mathbf{0}$ & 1 & 34 & 39 & 106 & تكرار & المجموع \\
\hline & & & & & 0.0 & 0.6 & 18.9 & 21.7 & 58.9 & $\%$ & النسبة المئوية \\
\hline
\end{tabular}

الثالث قد بلغ حوالي 4.8 بإنحراف معياري بلغ حوالي 0.5 وبقوة نسبية مرجحة بلغت حوالي 95\% مما يشير إلى وجود بلي

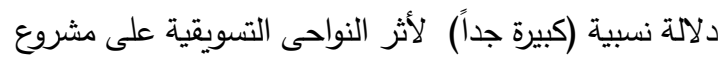
الصوب الزراعية لمحصول الفاصوليا بعينة الدراسة. كما تشير النتائج إلى أن هناك حوالي 85.8\% من عينة الدراسة يؤكدون على وجود أهمية كبيرة جداً لأثر النواحى التسويقية على مشروع الصوب الزراعية لمحصول الفاصوليا ، بينما أشار حوالي 7.5\% منهم إلى وجود أهمية كبيرة فقط ، بينما أشار حوالي 4.2\% إلى وجود أهمية متوسطة ، بينما أثار حوالي 0.8\% منهم إلى وجود أهمية صغيرة ، بينما أشار حوالي 1.7\% إلى عدم وجود أهمية لأثر النواحى التسويقية على مشروع الصوب الزراعية لمحصول الفاصوليا. وفى ضوء نتائج الجدول السابق وبترتيب نقاط المحورالثالث الخاص ترتيباً تنازلياً طبقاً للمتوسط المرجح والقوة النسبية
المحور الثالث : دور النواحى التسويقية في مشروع الصوب الزراعية لمحصول الفاصوليا بعينة الدراسة بمحافظة الاقهلية

يضم المحور الثالث دور النواحى التسويقية في مشروع الصوب الزراعية لمحصول الفاصوليا بعينة الدراسة بمحافظة الدقهلية حيث إثتمل على أربعة نقاط فرعية هى : 1. تذبذب أسعار المحاصيل المنتجة. 2. إستغلال تجار الجملة لمنتجى الصوب الزراعية. 3. بعد أماكن الإنتاج عن أماكن التسويق. 4. إرتفاع تكاليف النقل والتسويق وفيما يلى تفصيل لنقاط ذلك المحور : تبين من خلال نتائج جدول (7) والذى يتعلق بأثر النواحى التسويقية على مشروع الصوب الزراعية لمحصول الفاصوليا بعينة الدراسة بمحافظة الدقهلية أن المتوسط المرجح للمحور 
المرجحة لكل عبارة من عبارات المحور حيث تبين وفقاً الترتيب الثاني: جاء إستغلال تجار الجملة لمنتجى الصوب

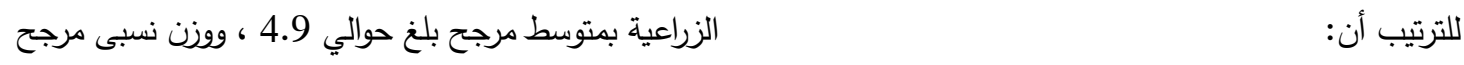

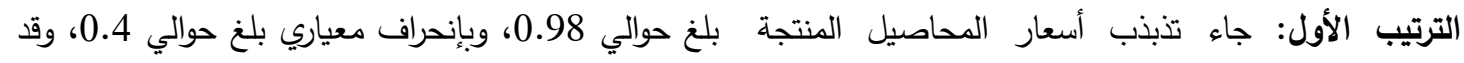

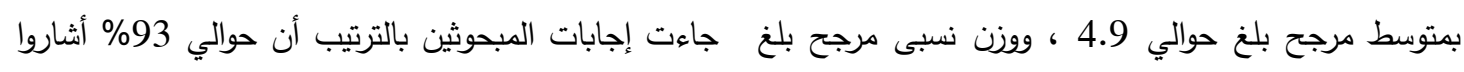

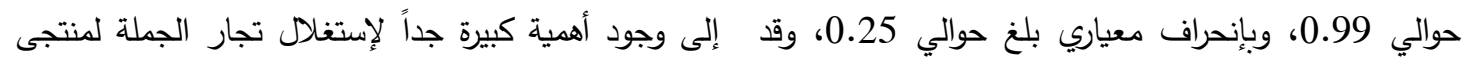

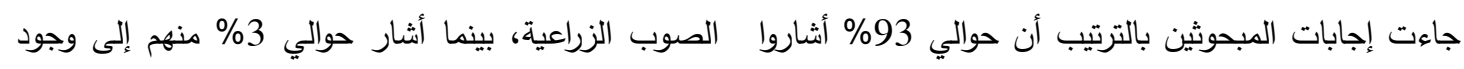

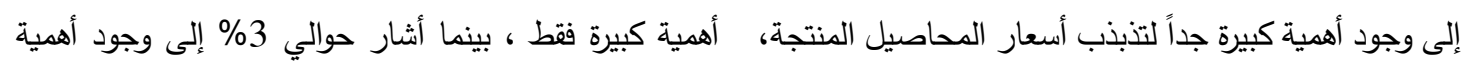

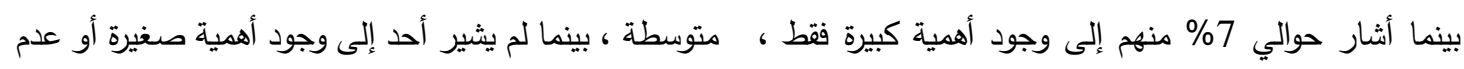

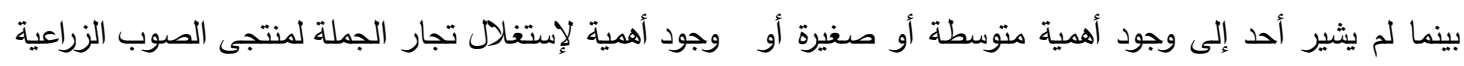
عدم وجود أهمية لتنبذب أسعار المحاصيل المنتجة.

جدول رقم (7) : دور النواحى التسويقية على مشروع الصوب الزراعية لمحصول الفاصوليا بعينة الداستة بمحافظة الدقهلية

\begin{tabular}{|c|c|c|c|c|c|c|c|c|c|c|c|}
\hline الترتيب & النتيجة & المرجحة & الانعراف & المتوسط & ليس له & صغير & متوسط & 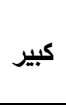 & كبير & & 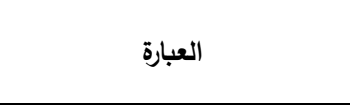 \\
\hline \multirow{2}{*}{1} & \multirow{2}{*}{ كبير جداً } & \multirow{2}{*}{0.99} & \multirow{2}{*}{0.25} & \multirow{2}{*}{4.9} & 0 & 0 & 0 & 2 & 28 & تكرار & 1- تذبذب أسعار المحاصيل \\
\hline & & & & & 0 & 0 & 0 & 7 & 93 & $\%$ & المنتجة \\
\hline \multirow{2}{*}{2} & \multirow{2}{*}{ كبير جداً } & \multirow{2}{*}{0.98} & \multirow{2}{*}{0.40} & \multirow{2}{*}{4.9} & 0 & 0 & 1 & 1 & 28 & 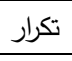 & 2- إستغلال تجار الجملة لمنتجى \\
\hline & & & & & 0 & 0 & 3 & 3 & 93 & $\%$ & الصوب الزراعية \\
\hline \multirow{2}{*}{3} & \multirow{2}{*}{ كبير جداً } & \multirow{2}{*}{0.95} & \multirow{2}{*}{0.64} & \multirow{2}{*}{4.7} & 0 & 0 & 3 & 2 & 25 & 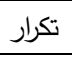 & 3- بعد أماكن الإنتاج عن أماكن \\
\hline & & & & & 0 & 0 & 10 & 7 & 83 & $\%$ & التسويق \\
\hline \multirow{4}{*}{4} & \multirow{2}{*}{ كبير جداً } & \multirow{2}{*}{0.89} & \multirow{2}{*}{1.17} & \multirow{2}{*}{4.4} & 2 & 1 & 1 & 4 & 22 & 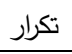 & \multirow{2}{*}{ 4- إرتفاع تكاليف النقل والتسويق } \\
\hline & & & & & 7 & 3 & 3 & 13 & 73 & $\%$ & \\
\hline & كبير جداً & 0.95 & 0.50 & 4.8 & 2 & 1 & 5 & 9 & 103 & تكرار & 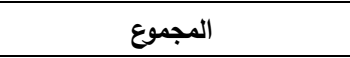 \\
\hline & & & & & 1.7 & 0.8 & 4.2 & 7.5 & 85.8 & $\%$ & النسبة المئوية \\
\hline
\end{tabular}

3 3 إلى وجود أهمية متوسطة ، بينما أشار حوالي 3\% منهح

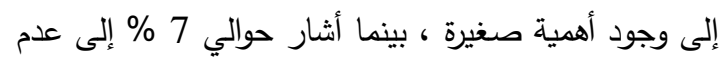
وجود أهمية لإرتفاع تكاليف النقل والتسويق. المحور الرابع : أثر جائحة فيرس كورونا المستجد على الإنى مشروع الصوب الزراعية لمحصول الفاصوليا بعينة الاراسة :

بمحافظة الدقهلية يشتمل المحور الرابع لأثر فيرس كورونا المستجد على مشروع

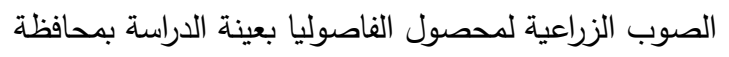

$$
\text { الدقهلية على ستة نقاط فرعية هى : }
$$

1. الأثر على إنتاج الصوب الزراعية. 2. الأثر على تسويق منتجات الصوب الزراعية.

$$
\text { 3. الأثر على هامش الربح. }
$$

4. الأثر على أسعار محاصيل الصوب الزراعية

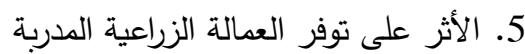
6. الأثر على تصدير محاصيل الصوب الزراعية
الترتيب الثالث: جاء بعد أماكن الإنتاج عن أماكن التسويق بمتوسط مرجح بلغ حوالي 4.7 ، ووزن نسبى مرجح بلغ الإن حوالي 0.95، وبإنحراف معياري بلغ حوالي 0.64، وقد جاءت إجابات المبحوثين بالترتيب أن حوالي 83\% أشاروا إلى وجود أهمية كبيرة جداً لبعد أماكن الإنتاج عن أماكن التسويق، بينما أشار حوالي 7\% منهم إلى وجود أهمية كبيرة

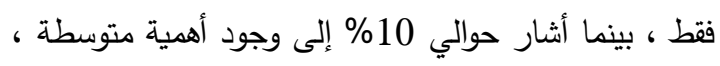
بينما لم يشير أحد إلى وجود أهمية صغيرة أو عدم وجود أهمية لبعد أماكن الإنتاج عن أماكن التسويق. الترتيب الرابع: جاء إرتفاع تكاليف النقل والتسويق بمتوسط مرجح بلغ حوالي 4.4 ، ووزن نسبى مرجح بلغ حوالي 0.89، وبإنحراف معياري بلغ حوالي 1.17، وقد جاءت إجابات المبحوثين بالترتيب أن حوالي 73\% أشاروا إلى وجود أهمية كبيرة جداً لإرتفاع تكاليف النقل والتسويق ، بينما أشار حوالي 13 منهم إلى وجود أهمية كبيرة فقط ، بينما أشار حوالي 
الترتيب الثالث: جاء الأثر على إنتاج الصوب الزراعية

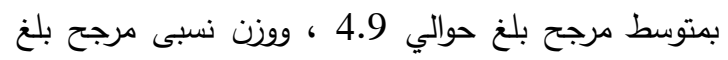

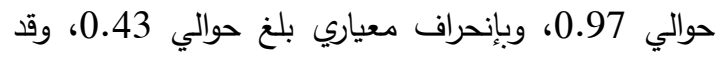

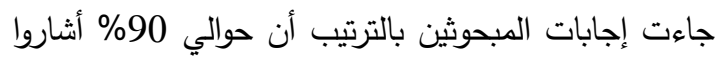
إلى وجود أهمية كبيرة جداً للأثر على إنتاج الصوب الترتي الزراعية

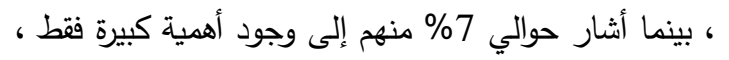

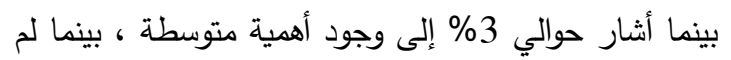

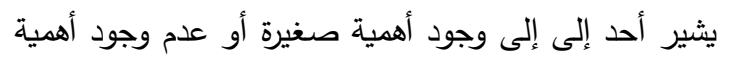
للأثر على إنتاج الصوب الزراعية.

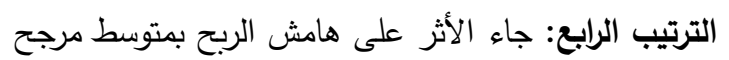

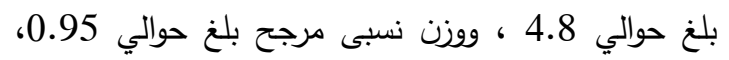

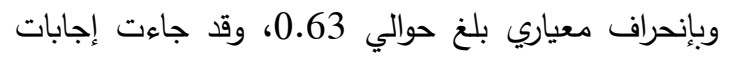

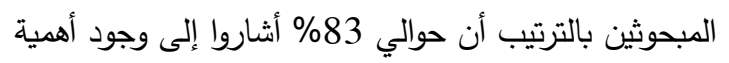

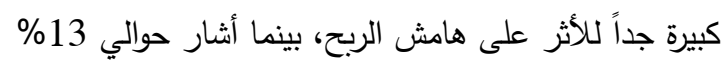

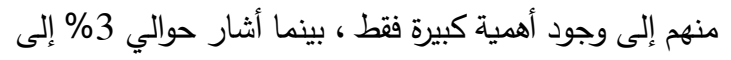

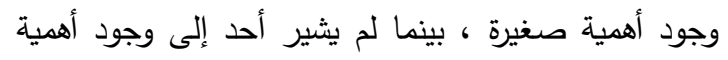

متوسطة أو عدم وجود أهمية للأثر على هامش الربح. الترتيب الخامس: جاء الأثر على تسويق منتجات الصوبة

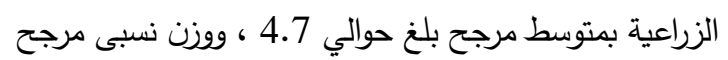

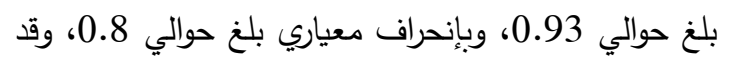
جاءت إجابات المبحوثين بالترتيب أن حوالي 80 \% 83 \% أشاروا

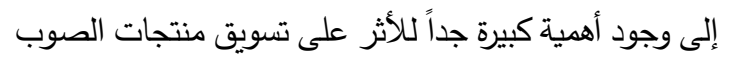

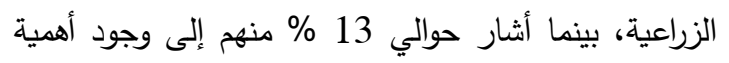
كبيرة فقط ، بينما أشار حوالي 7 \% إلى وجود أهمية صغيرة

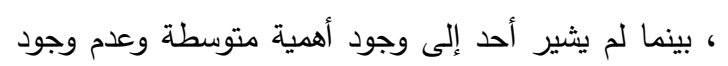
أهمية للأثر على تسويق منتجات الصوب الزبير الزباعية. الترتيب السادس: جاءت عبارة الأثر على تصدير محاصيل

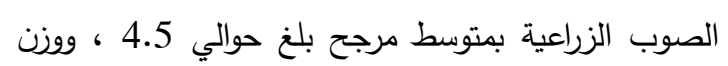

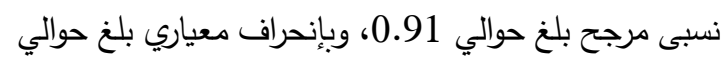
1.22، وقد جاءت إجابات المبحوثين بالترتيب أن حوالي 83

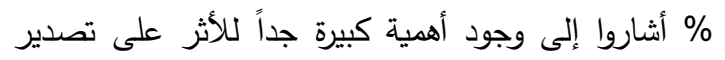

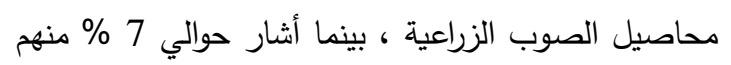

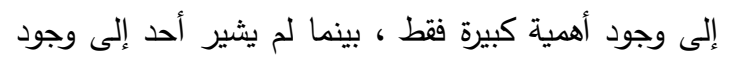

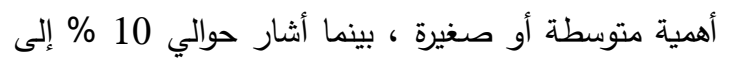

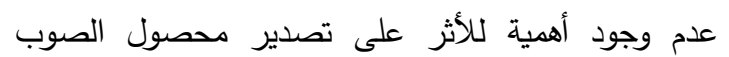

الزراعية
وفيما يلى تفصيل لعبارات ذلك المحور : تبين من خلال نتائج جدول (8) والذى يتعلق بأثر جائحة

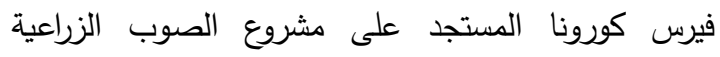

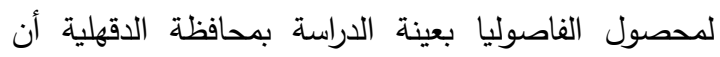
المتوسط المرجح للمحور الرابع قد بلغ حوالي 4.8 بإنحراف لـافئل

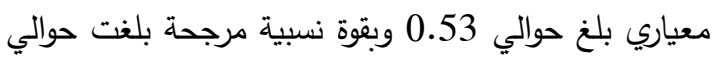

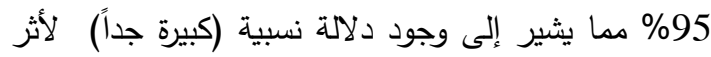

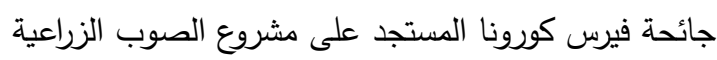
لمحصول الفاصوليا بعينة الدراسة. كما تثير النتائج إلى أن أن الن هناك حوالي 85.6\% من عينة الدراسة يؤكدون على وجود

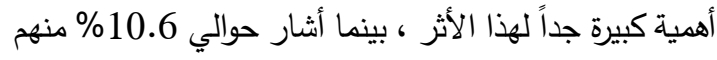

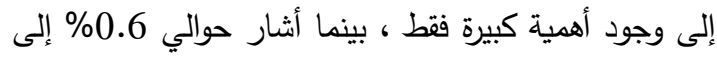

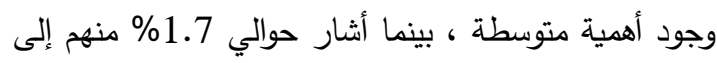

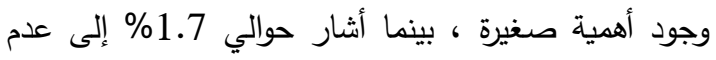

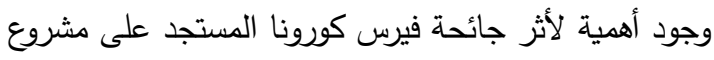
الصوب الزراعية لمحصول الفاصوليا.

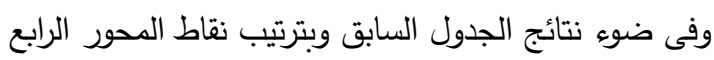
الخاص ترتيباً تنازلياً طبقاً للمتوسط المرجح والقوة النسبية المرجحة لكل عبارة من عبارات المحور حيث تبين وفقاً للترتيب أن: الترتيب الأول: جاء الأثر على توفر العمالة الزراعية المدربة

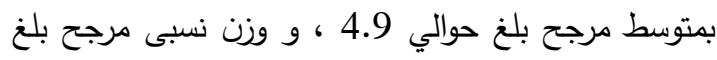

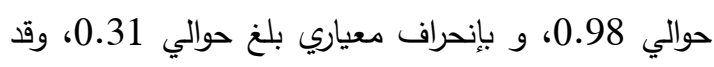

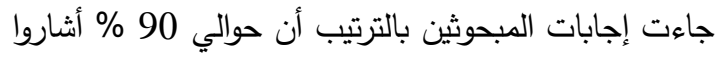

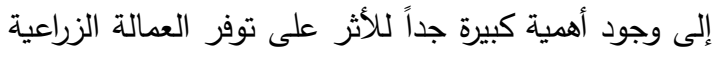

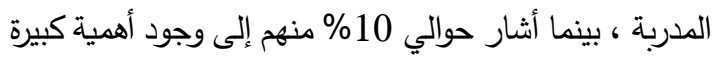

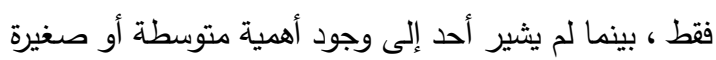
أو عدم وجود أهمية للأثر على توفر العمالة الزراعية المدربة.

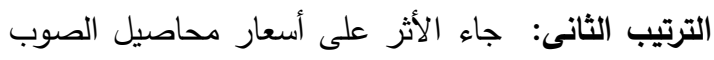

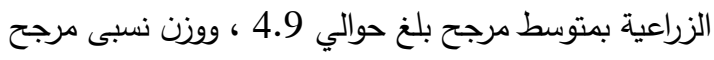

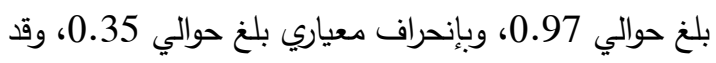

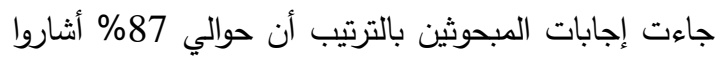

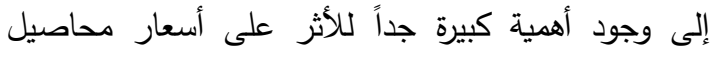

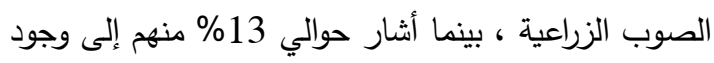
أهمية كبيرة فقط ، بينما لم يشير أحد إلى وجود أهمية متوسطة الهئ

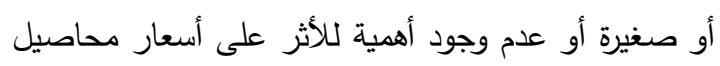
الصوب الزراعية. 
جدول رقم (8) : أثر جائحة فيرس كورونا المستجد على مشروع الصوب الزراعية لمحصول الفاصوليا بعينة الدراسة بمحافظة الدقهلية

\begin{tabular}{|c|c|c|c|c|c|c|c|c|c|c|c|}
\hline الترتيب & النتيجة & المرجحة & المعياري & المتوسط & ليس له & صغير & متوسط & 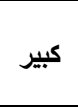 & كبير & & العبارة الع \\
\hline \multirow{2}{*}{3} & \multirow{2}{*}{ كبير جداً } & \multirow{2}{*}{0.97} & \multirow{2}{*}{0.43} & \multirow{2}{*}{4.9} & 0 & 0 & 1 & 2 & 27 & تكرار & 1- الأثر على إنتاج الصوب \\
\hline & & & & & 0 & 0 & 3 & 7 & 90 & $\%$ & الزراعية \\
\hline \multirow{2}{*}{5} & \multirow{2}{*}{ كبير جداً } & \multirow{2}{*}{0.93} & \multirow{2}{*}{0.80} & \multirow{2}{*}{4.7} & 0 & 2 & 0 & 4 & 24 & تكرار & 2- الأثر على تسويق منتجات \\
\hline & & & & & 0 & 7 & 0 & 13 & 80 & $\%$ & الصوب الزراعية \\
\hline \multirow{2}{*}{4} & \multirow{2}{*}{ كبير جداً } & \multirow{2}{*}{0.95} & \multirow{2}{*}{0.63} & \multirow{2}{*}{4.8} & 0 & 1 & 0 & 4 & 25 & تكرار & \multirow{2}{*}{ 3- الأثر على هامش الربح } \\
\hline & & & & & 0 & 3 & 0 & 13 & 83 & $\%$ & \\
\hline \multirow{2}{*}{2} & \multirow{2}{*}{ كبير جداً } & \multirow{2}{*}{0.97} & \multirow{2}{*}{0.35} & \multirow{2}{*}{4.9} & 0 & 0 & 0 & 4 & 26 & تكرار & 4- الأثر على أسعار محاصيل \\
\hline & & & & & 0 & 0 & 0 & 13 & 87 & $\%$ & الصوب الزراعية \\
\hline \multirow{2}{*}{1} & \multirow{2}{*}{ كبير جداً } & \multirow{2}{*}{0.98} & \multirow{2}{*}{0.31} & \multirow{2}{*}{4.9} & 0 & 0 & 0 & 3 & 27 & 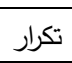 & 5- الأثر على توفر العمالة \\
\hline & & & & & 0 & 0 & 0 & 10 & 90 & $\%$ & الزراعية المدربة \\
\hline \multirow{4}{*}{6} & \multirow{2}{*}{ كبير جداً } & \multirow{2}{*}{0.91} & \multirow{2}{*}{1.22} & \multirow{2}{*}{4.5} & 3 & 0 & 0 & 2 & 25 & تكرار & 6- الأثرعلى تصدير محاصيل \\
\hline & & & & & 10 & 0 & 0 & 7 & 83 & $\%$ & الصوب الزراعية \\
\hline & كبير جداً & 0.95 & 0.53 & 4.8 & 3 & 3 & 1 & 19 & 154 & تكرار & المجموع \\
\hline & & & & & 1.7 & 1.7 & 0.6 & 10.6 & 85.6 & $\%$ & النسبة المئوية \\
\hline
\end{tabular}

لإجراء دراسة أهم العوامل المؤثرة على أثر فيرس كورونا المستجد على مشروع الصوب الزراعية لمحصول الفاصوليا بعينة الدراسة بمحافظة الدقهلية يجب اتباع الخطوات العلمية السليمة وهي وضع فروض الدراسة:

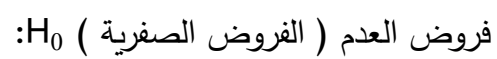
1- لا يوجد علاقة ذات دلالة إحصائية عند مستوى ثقة الفروفة 95 \%بين أثر النواحى التمويلية على مشروع الصوب الزراعية لمحصول الفاصوليا بعينة الدراسة و أثر فيرس كورونا المستجد على مشروع الصوب الزراعية لمحصول الفاصوليا بعينة الاراسة. 2- لا يوجد علاقة ذات دلالة إحصائية عند مستوى ثقة 95 \%بين أثر النواحى الإنتاجية على مشروع الصوب الزراعية لمحصول الفاصوليا بعينة الدراسة و أثر فيرس كورونا المستجد على مشروع الصوب الزراعية لمحصول الفاصوليا بعينة الاراسة.

3- لا يوجد علاقة ذات دلالة إحصائية عند مستوى ثقة 95 \%بين أثز النواحى التسويقية على مشروع الصوب الزراعية لمحصول الفاصوليا بعينة الدراسة و أثر فيرس كورونا المستجد على مشروع الصوب الزراعية لمحصول الفاصوليا بعينة الدراسة.
وقد تبين من نتائج دراسة نتائج المحاور الأربعة لعينة الدراسة

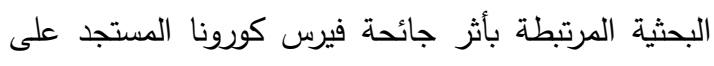
مشروع الصوب الزراعية لمحصول الفاصوليا بعينة الدراسة بمحافظة الدقهلية أن المحور الأول وهو أثر النواحى التمويلية على مشروع الصوب الزراعية لمحصول الفاصوليا ويشمل ثلاث نقاط قد حصل على 4.2 أي كبير جداً حسب مقياس ليكارت الخماسي Likart Scale. في حين تبين أن المحور الثاني وهو أثز النواحى الإنتاجية على مشروع الصوب الزراعية لمحصول الفاصوليا بعينة الدراسة ويشمل ستة نقاط قد حصل على 4.2 أي كبير جداً ، كما تبين أن المحور الثالث وهو أثر النواحى التسويقية على مشروع الصوب الزراعية لمحصول الفاصوليا بعينة الدراسة ويشمل ثلاث نقاط قد حصل على 4.8 أي كبير جداً. في حين تبين أن المحور الرابع وهو أثر جائحة فيرس كورونا المستجد على مشروع الصوب الزراعية لمحصول الفاصوليا بعينة الدراسة بمحافظة الدقهلية ويشمل ستة نقاط؛ قد حصل على 4.8 أي كبير جداً حسب مقياس ليكارت الخماسي. ثالثا : دراسة أهم العوامل المؤثرة على أثر جائحة فيرس كورونا المستجد على مشروع الصوب الزراعية لمحصول الفاصوليا بعينة الدراسة بمحافظة الدقهلية 
المستجد على مشروع الصوب الزراعية للحصول الفاصوليا

$$
\text { بعينة الدراسة. }
$$

3- يوجد علاقة ذات دلالة إحصائية عند مستوى ثقة 95 \%بين أثر النواحى التسويقية على مشروع الصوب دالتها الزراعية لمحصول الفاصوليا بعينة الدراسة و أثر فيرس كورونا المستجد على مشروع الصوب الزراعية للحصول الفاصوليا

بعينة الدراسة.
1- يوجد علاقة ذات دلالة إحصائية عند مستوى ثقة 95 \%بين أثر النواحى التمويلية على مشروع الصوب دلالية الزراعية

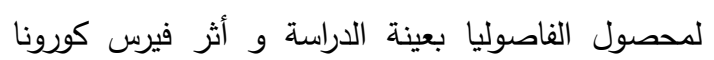
المستجد على مشروع الصوب الزراعية لمحصول الفاصوليا بعينة الدراسة. 2 يوجد علاقة ذات دلالة إحصائية عند مستوى ثقة 95

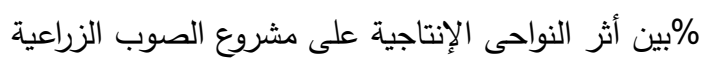

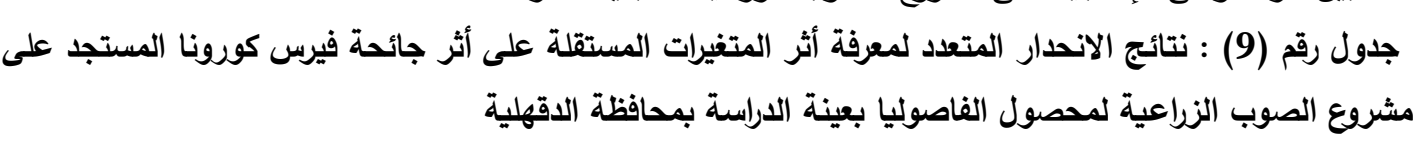

\begin{tabular}{|c|c|c|c|}
\hline مستوى الدلالة & قيمة ت & معامل الانحدار & المتغير \\
\hline 0.021 & 2.45 & 2.023 & ثابت الدالة \\
\hline \multirow[t]{3}{*}{0.002} & 3.34 & 0.577 & أثر النواحى التسويقية \\
\hline & 0.534 & & معامل التحديد \\
\hline & $11.2 * *$ & & قيمة ف \\
\hline
\end{tabular}

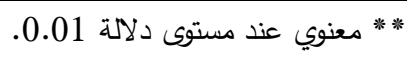
المصدر : جمعت وحسبت من استمارات الاستبيان بعينة الدراسة . عند مستوى ثقة بين أثر النواحى الإنتاجية على مشروع

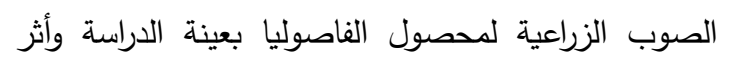

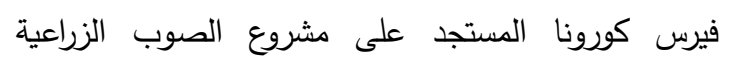
لمحصول الفاصوليا بعينة الدراسة ورفض الفرض البن البديل

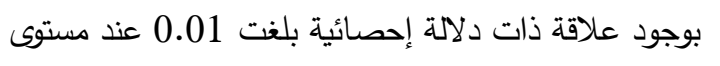

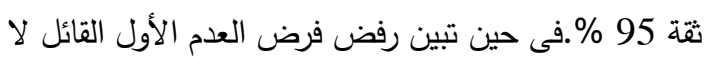

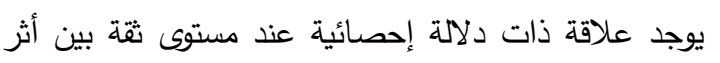

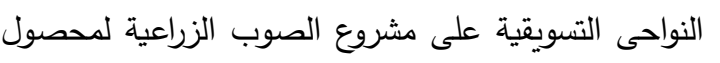

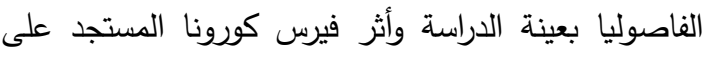

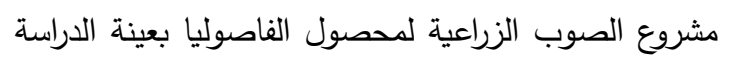

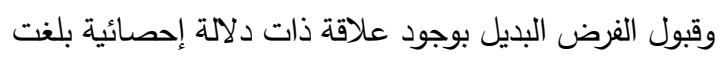

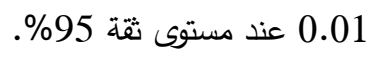
وقد تبين من دراسة العوامل المؤثرة على أثر فيرس كورونا المستجد على مشروع الصوب الزراعية لمحصول الفاصوليا

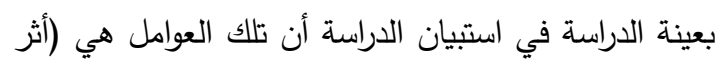

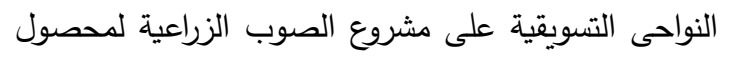
الفاصوليا بعينة الدراسة) حيث تمثل متغيرات هامة في التأثير على أثر فيرس كورونا المستجد على مشروع الصوب الزينة الزراعية لمحصول الفاصوليا بعينة الدراسة.

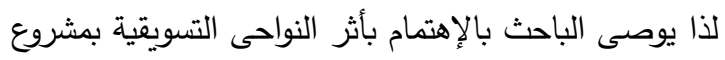

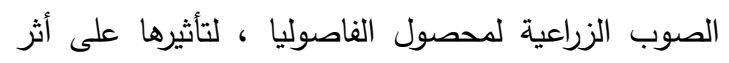

وقد تم تحديد المتغيرات المستقلة والتابعة، حيث تمثلت المتغيرات المستقلة في المحور الأول (النواحى التمويلية) والثانى (النواحى الإنتاجية) والثالث (النواحى التسويقية) في لالتئي حين تمثل المتغير التابع في أثر المتغيرات المستقلة على أثراني

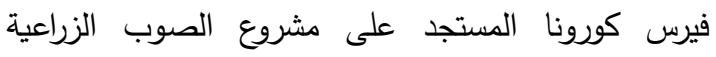
لمحصول الفاصوليا بعينة الدراسة (Y)، وقد تبين من نتائج

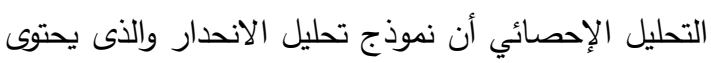
على المتغير التفسيرى وهو المحور الثالث يفسر حودالي التئي

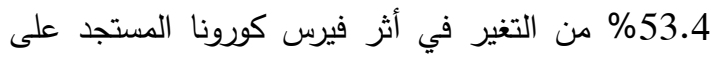
مشروع الصوب الزراعية لمحصول الفاصوليا بعينة الدراسة كردئ وذلك عند درجة ثقة 95\% ومستوى دلالة إحصائية يبلغ

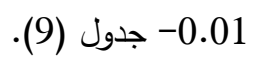
نتائج اختبار الفروض:

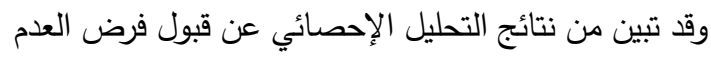
الأول القائل لا يوجد علاقة ذات دلالة إحصائية عند مستوى لإئل

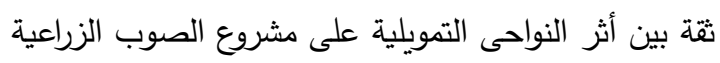

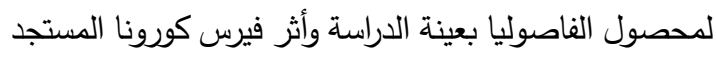
على مشروع الصوب الزراعية لدحصول الفاصوليا بعينة الدراسة ورفض الفرض البديل بوجود علاقة ذات دلالة

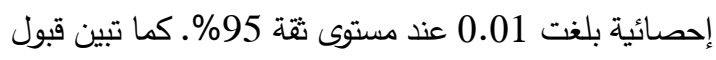
فرض العدم الأول القائل لا يوجد علاقة ذات دلالة إحصائية 
يعنى وجود فرقاً معنوياً ذو دلالة إحصائية بين القيمة المحسوبة والقيمة الجدولية ، ولهذا نقبل فرضية الدراسة ونرفض الفرضية الصفرية بوجود مشكلة عدم وجود تسهيلات إئتمانية بنكية للحصول على القروض.

فى حين تبين بالنسبة لمشكلة ضعف قيمة القروض التمويلية تبين أن قيمة كاى2 بلغت حوالى 27.87 وهى أكبر من قيمة كاى2 الجدولية البالغة حوالى 7.815 عند مستوى ثقة 95 \% وبدرجة حرية 3 ، وهذا يعنى وجود فرقاً معنوياً ذو دلالة

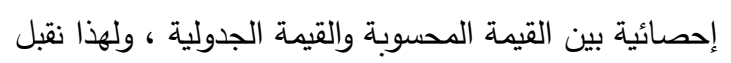
فرضية الدراسة ونرفض الفرضية الصفرية بوجود مشكلة ضعف قيمة القروض التمويلية. كما تبين بالنسبة لمشكلة إرتفاع أسعارالأسمدة الكيماوية أن قيمة كاى2 بلغت حوالى 9.8 وهى أكبر من قيمة كاى2 الجدولية البالغة حوالى 5.991 عند مستوى ثقة وبدرجة حرية 2 ، وهذا يعنى وجود فرقاً معنوياً ذو دلالة إحصائية بين القيمة المحسوبة والقيمة الجدولية ، ولهذا نقبل وليل فرضية الدراسة ونرفض الفرضية الصفرية بوجود مشكلة في بي إرتغاع أسعار الأسمدة الكيماوية.

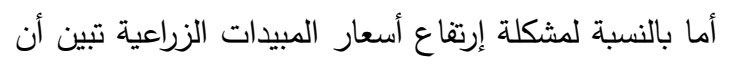
قيمة كاى2 بلغت حوالى 16.13 وهى أكبر من قيمة كاى2 2

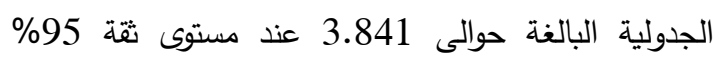
وبدرجة حرية 1 ، وهذا يعنى وجود فرقاً معنوياً ذو دلالة

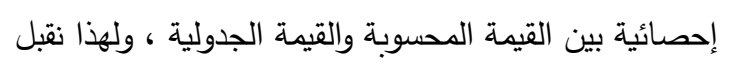
فرضية الدراسة ونرفض الفرضية الصفرية بوجود مشكلة ، إرتقاع أسعار المبيدات الزراعية. فى حين تبين بالنسبة لمشكلة إرتفاع تكاليف إنثاء الصوب إنباء الزراعية تبين أن قيمة كاى2 بلغت حوالى 16.2 وهى أكبر من قيمة كاى2 الجدولية البالغة حوالى 5.991 عند مستوى لنى ثقة 95\% وبدرجة حرية 2 ، وهذا يعنى وجود فرقاً معنوياً ذو لون دلالة إحصائية بين القيمة المحسوبة والقيمة الجدولية ، ولهذا نقبل فرضية الدراسة ونرفض الفرضية الصفرية بوجود مشكلة إرتفاع تكاليف إنثاء الصوب الزراعية. كما تبين بالنسبة لمشكلة إنخفاض الخبرة فى مجال الصوب الزراعية تبين من
فيرس كورونا المستجد على مشروع الصوب الزراعية لمحصول الفاصوليا بعينة الدراسة.

رابعاً : أهم المشاكل والمعوقات التى تواجه مزارعى محصول

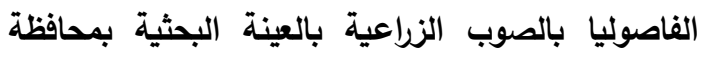
الدقهلية يوضح الجدول (10) أهم المشاكل والمعوقات التى تواجه مزارعى محصول الفاصوليا بالصوب الزراعية بالعينة البحثية ، حيث أشار ما نسبتهم حوالى 50.8 \% أن أهم المشاكل برأل والمعوقات تمثلت فى إرتغاع أسعار مستلزمات الإنتاج الزراعى بصفة عامة و أسعار الأسمدة بصفة خاصة، بينما أجاب حوالى 12.9 \% بوجود مشكلة إرتفاع أسعار التقاوى وإنتشار التقاوى غيرالمحسنة منخفضة الإنتاجية ، يليها مشكلة ضعف دورالإرشاد الزراعي بالتعريف بأهمية المشروعات الصغيرة وخاصة الصوب الزراعية حيث بلغت نسبتها حوالى 11.4 \% ، ثم مشكلة وجود تعقيدات إئمانية وبنكية حيث بلغت نسبتها حوالى 9.8 \% ، بينما أجاب حوالى 8.3 \% بوجود مشكلة إرتفاع أسعار مستلزمات إنثاء الصوب

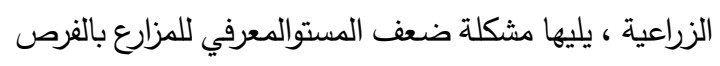

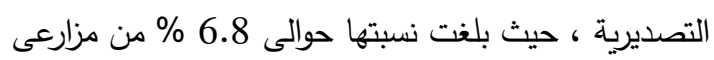
محصول الفاصوليا بالصوب الزراعية بالعينة البحثية

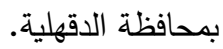
أما بالنسبة لهشكلة إرتفاع أسعار الفائدة على القروض تبين

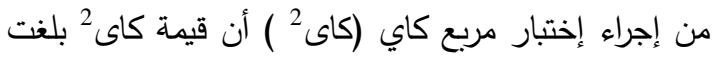
حوالى 29.6 وهى أكبر من قيمة كاى2 الجدولية البالغة

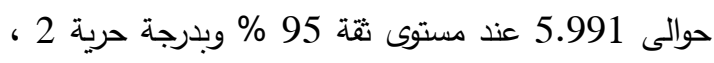
وهذا يعنى وجود فرقاً معنوياً ذو دلالة إحصائية بين القيمة المحسوبة والقيمة الجدولية ، ولهذا نقبل فرضية الدراسة ونرفض الفرضية الصفرية بوجود مشكلة في إرتفاع أسعارالفائدة على القروض. أما بالنسبة لمشكلة عدم وجود تسهيلات إئتمانية بنكية للحصول على القروض تبين أن قيمة كاى² بلغت حوالى 37.73 وهى أكبر من قيمة كاى2 الجدولية البالغة حوالى لبعل 7.815 عند مستوى ثقة 95 \% وبدرجة حرية 3 ، وهذا 
فرقاً معنوياً ذو دلالة إحصائية بين القيمة المحسوبة والقيمة الجدولية ، ولهذا نقبل فرضية الدراسة ونرفض الفرضية الصفرية بوجود مشكلة إستغلال تجار الجملة لمنتجى الصوب لهب

الزراعية.

فى حين تبين بالنسبة لمشكلة بعد أماكن الإنتاج عن أماكن

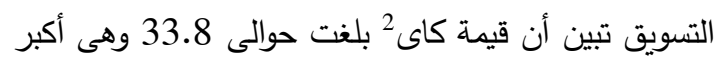
من قيمة كاى2 الجدولية البالغة حوالى 5.991 عند مستوى

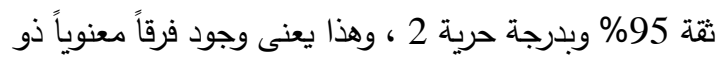
دلالة إحصائية بين القيمة المحسوبة والقيمة الجدولية ، ولهذا نقبل فرضية الدراسة ونرفض الفرضية الصفرية بوجود مشكلة بعد أماكن الإنتاج عن أماكن التسويق. كما تبين بالنسبة لمشكلة إرتقاع تكاليف النقل والتسويق تبين

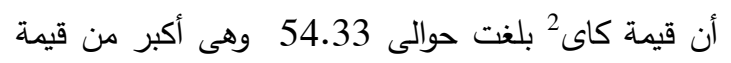

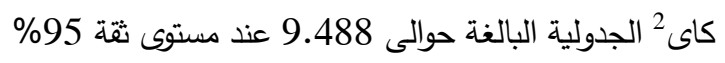
وبدرجة حرية 4 ، وهذا يعنى وجود فرقاً معنوياً ذو دلالة إحصائية بين القيمة المحسوبة والقيمة الجدولية ، ولهذا نقبل فرضية الدراسة ونرفض الفرضية الصفرية بوجود مشكلة إرتفاع تكاليف النقل والتسويق. أما بالنسبة لمشكلة الأثر على إنتاج الصوب الزراعية تبين أن قيمة كاى2 بلغت حوالى 43.4 وهى أكبر من قيمة

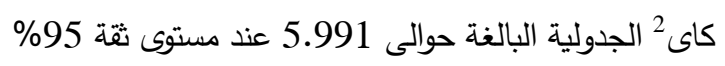
وبدرجة حرية 3 ، وهذا يعنى وجود فرقاً معنوياً ذو دلالة

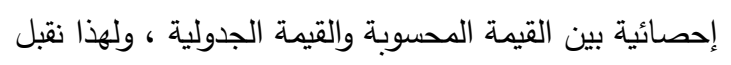
فرضية الدراسة ونرفض الفرضية الصفرية بوجود مشكلة الأثر لئر على إنتاج الصوب الزراعية. فى حين تبين بالنسبة لمشكلة الأثر على تسويق منتجات الصوب الزراعية تبين أن قيمة كاى2 بلغت حوالى 29.6 وهى أكبر من قيمة كاى2 الجدولية البالغة حوالى 5.991 عند مستوى ثقة 95\% وبدرجة حرية 2 ، وهذا يعنى وجود

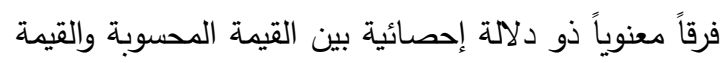
الجدولية ، ولهذا نقبل فرضية الدراسة ونرفض الفرضية الصفرية بوجود مشكلة الأثر على تسويق منتجات الصوب

الزراعية.
إجراء إختبار كاى² أن قيمة كاى² بلغت حوالى 6.2 وهى أكبر من قيمة كاى² الجدولية البالغة حوالى 5.991 عند مستوى ثقة 95\% وبدرجة حرية 2 ، وهذا يعنى وجود فرقاً معنوياً ذو دلالة إحصائية بين القيمة المحسوبة والقيمة الجدولية ، ولهذا نقبل فرضية الدراسة ونرفض الفرضية

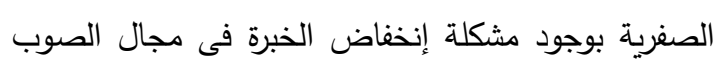
الزراعية.

أما بالنسبة لمشكلة الأمراض والآفات التى تصيب محاصيل الصوب الزراعية تبين أن قيمة كاى2 بلغت حوالى 12.2

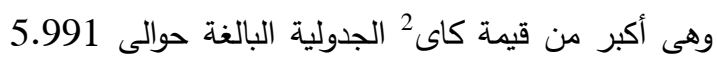
عند مستوى ثقة 95\% وبدرجة حرية 2 ، وهذا يعنى وجود فرقاً معنوياً ذو دلالة إحصائية بين القيمة المحسوبة والقيمة

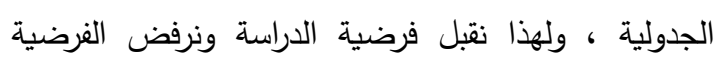

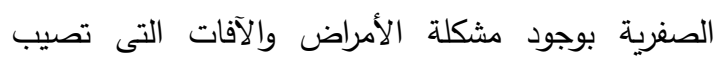

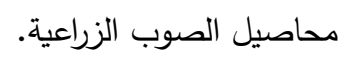
فى حين تبين بالنسبة لمشكلة إرتقاع أجور الأيدى العاملة تبين أن قيمة كاى² بلغت حوالى 8.67 وهى أكبر من قيمة

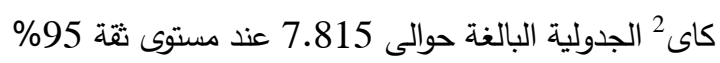
وبدرجة حرية 3 ، وهذا يعنى وجود فرقاً معنوياً ذو دلالة لهالة

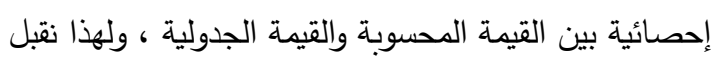
فرضية الدراسة ونرفض الفرضية الصفرية بوجود مشكلة إرتفاع أجور الأيدى العاملة.

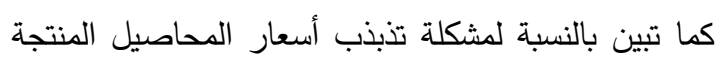

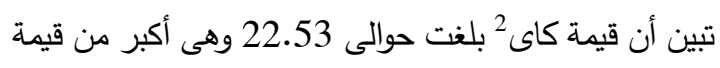

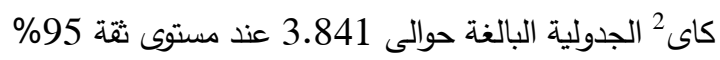
وبدرجة حرية 1 ، وهذا يعنى وجود فرقاً معنوياً ذو دلالة

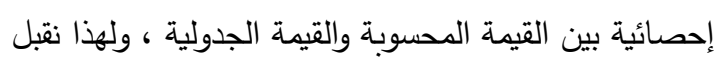
فرضية الدراسة ونرفض الفرضية الصفرية بوجود مشكلة تذبذب أسعار المحاصيل المنتجة. أما بالنسبة لمشكلة إستغلال تجار الجملة لهنتجى الصوب الزراعية تبين أن قيمة كاى2 بلغت حوالى 48.6 وهى أكبر من قيمة كاى2 الجدولية البالغة حوالى 5.991 عند مستوى ثقة 95\% وبدرجة حرية 1 ، و هذا يعنى وجود 
كما تبين بالنسبة لمشكلة الأثر على هامش الربح تبين أن فى حين تبين بالنسبة لمشكلة الأثر على توفر العمالة الزراعية قيمة كاى2 بلغت حوالى 34.2 وهى أكبر من قيمة كاى2

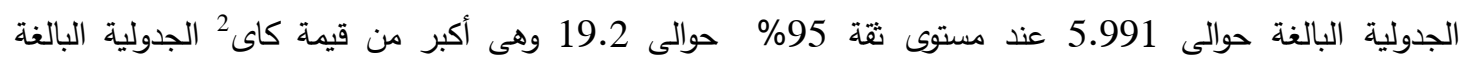

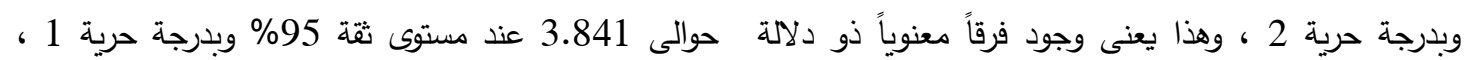
إحصائية بين القيمة المحسوبة والقيمة الجدولية ، ولهذا نقبل وهذا يعنى وجود فرقاً معنوياً ذو دلالة إحصائية بين القيمة فرضية الدراسة ونرفض الفرضية الصغرية بوجود مشكلة الأثر المحسوبة والقيمة الجدولية ، ولهذا نقبل فرضية الدراسة ونرفض الفرضية الصفرية بوجود مشكلة الأثر على توفر على هامش الربح.

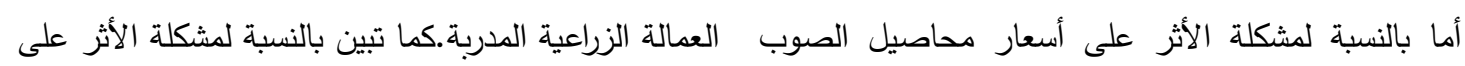
الزراعية تبين أن قيمة كاى2 بلغت حوالى 16.13 وهى أكبر تصدير محاصيل الصوب الزراعية تبين من إجراء إختبار من قيمة كاى2 الجدولية البالغة حوالى 3.841 عند مستوى كاى² أن قيمة كاى² بلغت حوالى 33.8 وهى أكبر من قيمة

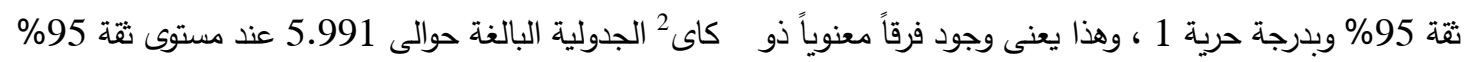

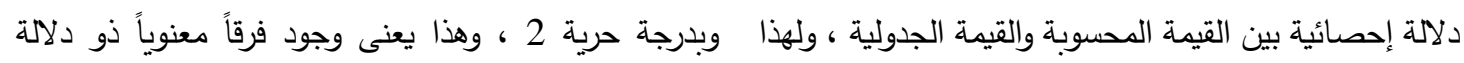

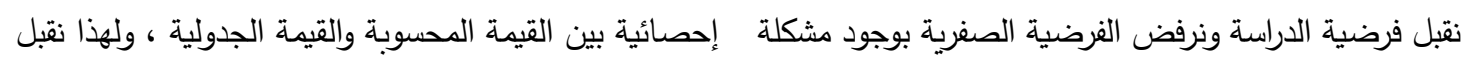

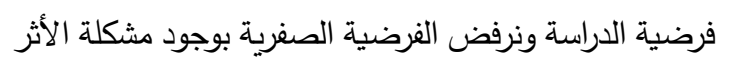
الأثر على أسعار محاصيل الصوب الزراعية.

$$
\text { على تصدير محاصيل الصوب الزراعية. }
$$

جدول (10) نتائج تحليل مربع كاى لأهم المشاكل والمعوقات التى تواجه مزارعى محصول الفاصوليا بالصوب الزراعية

\begin{tabular}{|c|c|c|c|c|}
\hline القيمة الجدولية القية & الدرية & معنوية الإحتمال & كاى & المثكلة \\
\hline 5.991 & 2 & 0.000 & 29.60 & 1- إرتفاع أسعار الفائدة على القروض \\
\hline 7.815 & 3 & 0.000 & 37.73 & 2- عدم وجود تسهيلات إئتمانية بنكية للحصول على القروض \\
\hline 7.815 & 3 & 0.000 & 27.87 & 3- ضعف قيمة القروض التمويلية \\
\hline 5.991 & 2 & 0.007 & 9.80 & 1- 1إتفاع أسعار الأسمدة الكيماوية \\
\hline 3.841 & 1 & 0.000 & 16.13 & 2- إرتفاع أسعار المبيدات الزراعية \\
\hline 5.991 & 2 & 0.000 & 16.20 & 3- إرتفاع تكاليف إنشاء الصوب الززاعية \\
\hline 5.991 & 2 & 0.045 & 6.20 & 4- إنخفاض الخبرة فى مجال الصوب الزراعية \\
\hline 5.991 & 2 & 0.002 & 12.20 & 5- الأمراض والآفات التى تصيب محاصيل الصوب الزراعية \\
\hline 7.815 & 3 & 0.034 & 8.67 & 6- 6 إرتفاع أجور الأيدى العاملة \\
\hline 3.841 & 1 & 0.000 & 22.53 & 1- تذبذب أسعار المحاصيل المنتجة \\
\hline 5.991 & 2 & 0.000 & 48.60 & 2- إستغلال تجار الجملة لننتجى الصوب الزراعية \\
\hline 5.991 & 2 & 0.000 & 33.80 & 3- بعد أماكن الإنتاج عن أماكن التسويق \\
\hline 9.488 & 4 & 0.000 & 54.33 & 4- إرتفاع تكاليف النقل والتسويق \\
\hline 5.991 & 2 & 0.000 & 43.40 & 1- الأثر على إنتاج الصوب الزراعية \\
\hline 5.991 & 2 & 0.000 & 29.60 & 2- الأثر على تسويق منتجات الصوب الززاعية \\
\hline 5.991 & 2 & 0.000 & 34.20 & 3- الأثر على هامش الربح \\
\hline 3.841 & 1 & 0.000 & 16.13 & 4- الأثر على أسعار محاصيل الصوب الزراعية \\
\hline 3.841 & 1 & 0.000 & 19.20 & 5- الأثر على توفر العمالة الزراعية المدربة \\
\hline 5.991 & 2 & 0.000 & 33.80 & 6- الأثر على تصدير محاصيل الصوب الززاعية \\
\hline
\end{tabular}


\% ب يليها خفض أسعار التقاوى ونشر التقاوى المحسنة مرتفعة الإنتاجية بحوالى 12.9\%، يلئ خليها زيادة دور الإرشاد الزراعي لئي

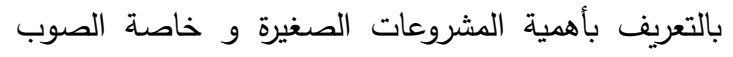
الزراعية بحوالى 11.4 \% ، يليها عمل تسهيلات إئتمانية و بنكية بحوالى 9.8 \% ،يليها خفض أسعار مستلزمات إنثاء الصوب الزراعية بحوالى 8.3 \% ، ثم تسهيل معرفة الزارع

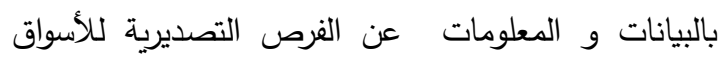
الخارجية بحوالى 6.8 \% - جدول رقم (11).
خامساً :أهم المقترحات من وجهة نظر مزارعى الصوب الزراعية لمحصول الفاصوئيا بعينة الدراسة: التالي التوصيات المقترحة من وجهة نظر مزارعى الصوب الزراعية لمحصول الفاصوليا بعينة الدراسة بمحافظة الدقهلية

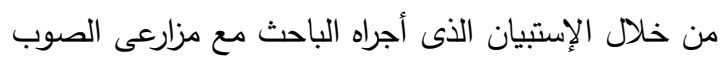
الزراعية لدحصول الفاصوليا بعينة الدراسة بمحافظة الدقهلية. حيث تبين أن أهم تلك المقترحات تمثلت في خفض أسعار الأسمدة ومستلزمات الإنتاج الزراعى حيث مثلت حوالى لثي

جدول رقم (11) : التوصيات المقترحة من وجهة نظر مزارعى الصوب الزراعية لمحصول الفاصوليا بعينة الدراسة بمحافظة

الدقهلية - - الدال

\begin{tabular}{|c|c|c|}
\hline$\%$ & العدد & التوصيــــــة \\
\hline 50.8 & 67 & خفض أسعار الأسمدة ومستلزمات الإنتاج الزراعى \\
\hline 12.9 & 17 & خفض أسعار التقاوى ونثر التقاوى المحسنة مرتفعة الإتتاجية \\
\hline 11.4 & 15 & زيادة دور الإرشاد بالتعريف بأهمية المشروعات الصغيرة وخاصة الصوب الززاعية \\
\hline 9.8 & 13 & عمل تسهيلات إيتمانية وبنكية \\
\hline 8.3 & 11 & خفض أسعار مستلزمات الصوب \\
\hline 6.8 & 9 & تسهيل معرفة المزارع بالفرص التصديرية للأسواق الخارجية \\
\hline 100 & 132 & 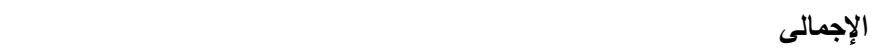 \\
\hline
\end{tabular}

المصدر: جمعت وحسبت من استمارات الاستبيان بعينة الدراسة .

6- عمل تسهيلات إئتمانية و بنكية لتشجيع الثباب

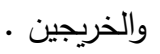

7- زيادة دورالإشاد الزراعي للتعريف بأهمية المشروعات

الصغيرة و خاصة الصوب الزراعية.

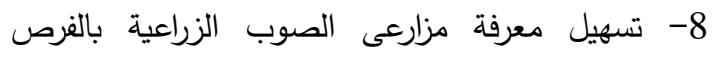

$$
\text { التصديرية للأسواق الخارجية . }
$$

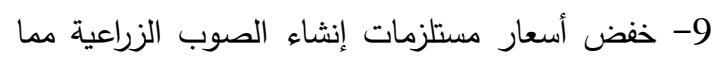

يقلل من التكاليف الإنشائية و يحث المستثمر على النياء لصني

$$
\text { الإستثمار فى تلك المشاريع. }
$$

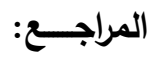

1.الموقع الإكترونى للجهاز المركزى للتعبئة العامة

والآحصاء 2. الموقع الإكترونى لقطاع الثئون الإقتصادية

http://agri.aljeelalmoshreq.com

3. إبراهيم حمدان صقر وآخرون ، دراسة اقتصادية لتكاليف

إنتاج البندورة تحت ظروف الزراعة المحمية خلال

الموسم الطويل في منطقة بانياس، سورية ، المجلة

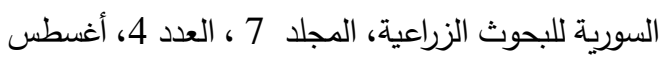

ومن خلال النتائج التي توصل إليها البحث أمكن إقتراح

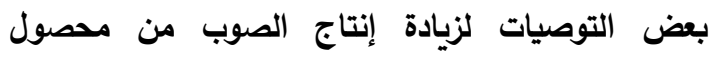
الفاصوليا بالصوب الزراعية بمحافظة الدقهلية زيادة عدد النباتات في الصوبة الزراعية للوصول للسعة المبها المزرعية المثلى لإنتاج محصول الفاصوليا.

2- توجيه الدعم لمزارعى الصوب مما يؤدى لتثجيع زراعة

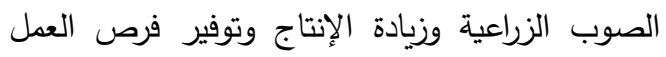

$$
\text { للثباب والخريجين. }
$$

3- الإهتمام بتسويق محصول الفاصوليا الخضراء لزيادة

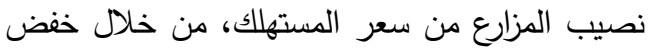

$$
\text { التكاليف الإنتاجية والتسويقية. }
$$

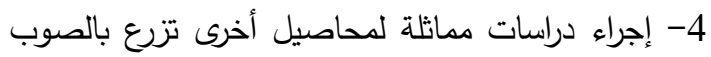

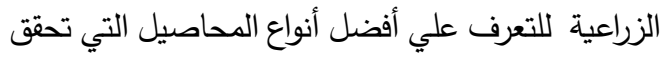

$$
\text { إقتصاد السعة. }
$$

5- خفض أسعار التقاوى والأسمدة و غيرها من مستلزمات

الإنتاج الزراعى و نشر التقاوى المحسنة مرتفعة الإنتاجية

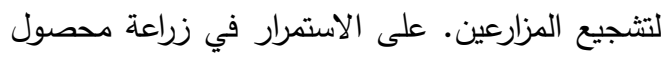

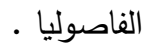




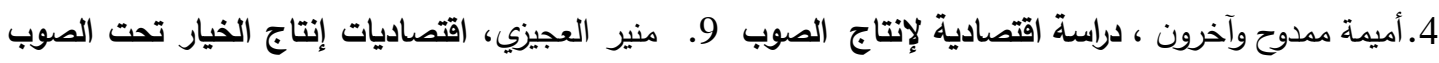

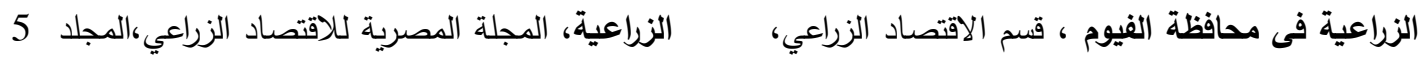

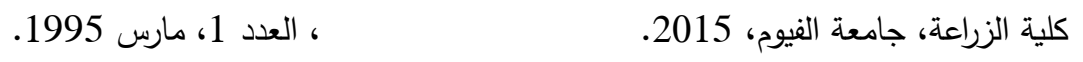

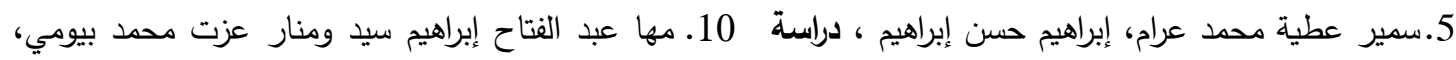

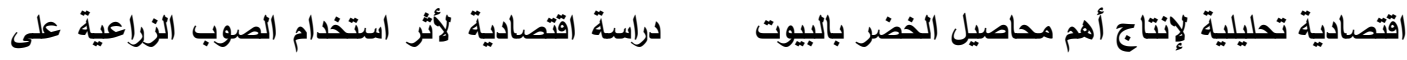

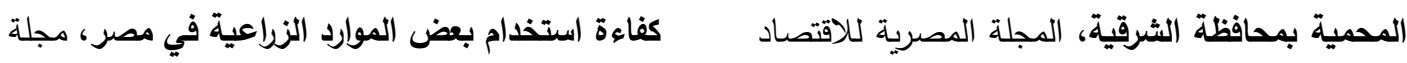

الزراعى، المجلد العشرون، العدد الأول، مارس 2010. أسيوط للعلوم الزراعية،المجلد الخمسون، العدد الأول، رقم

6. ضياء الحق إبراهيم ومعتز عليو مصطفى أحمد ، كفاءة التسلسل الدولى

إنتاج بعض محاصيل الخضر تحت نظام الزراعة 11. ممدوح البدرى محمد ، كفاءة ومشاكل إستخدام الأسمدة

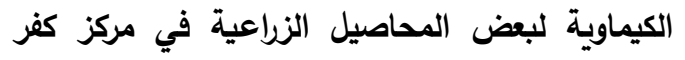

الدوار بمحافظة البحيرة، مجلة البحوث الزراعية ، جامعة الزئة

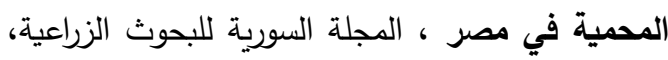

كفر الشيخ ، المجلد 42 ، العدد الأول ، مارس 2016.

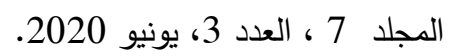

12. Johnston, J., Econometric Methods, 3rd,

McGraw-Hill Book Company, New

York, 1984.

Mamdouh Elbadry and others, An Economic

Study of the Marketing Efficiency for the

Most Important Crops and Agricultural

Commodities in Egypt, Third International

Conference on Advances in Social Science,

Management and Human Behavior

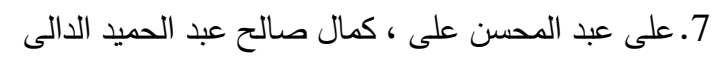

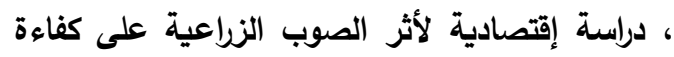

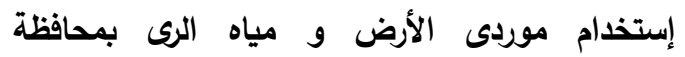

الإسماعيلية ، مجلة العلوم الإجتماعية والإقتصادية

الزراعية ، المجلد الثانى، العدد الرابع، 2013.

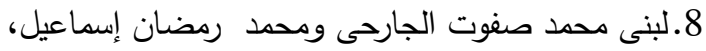

دراسة اقتصادية لإنتاج الفاصوليا الخضراء بالصوب ومداء

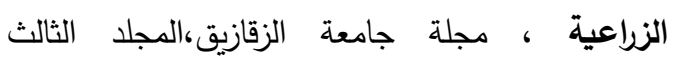

والعشرون، العدد الثالث، ، 2018. 